\title{
Transiently Selective Activation of Phosphoinositide Turnover in Layer V Pyramidal Neurons After Specific mGluRs Stimulation in Rat Somatosensory Cortex During Early Postnatal Development
}

\author{
J. A. Bevilacqua, ${ }^{1}$ C. Peter Downes, ${ }^{2}$ and Pedro R. Lowenstein ${ }^{1}$ \\ 'Laboratory of Cellular and Molecular Neurobiology, Physiology Unit, School of Molecular and Medical Biosciences, \\ University of Wales College of Cardiff, Cardiff CF1 3US and '2Department of Biochemistry, University of Dundee, \\ Dundee DD1 4HN, United Kingdom
}

Biochemical analysis of muscarinic- and metabotropic-glutamate receptor stimulated phosphoinositide (PI) turnover in rat cortical preparations during the first three weeks of postnatal development indicates the existence of a transiently increased accumulation of labeled inositol polyphosphates during the first postnatal week (Gonzales and Crews, 1985; Dudek et al., 1989). We now report for first time the visualization of those neurons responding with increased PI turnover to glutamatergic or cholinergic-receptor stimulation in rat somatosensory cortex during early postnatal development utilizing a recently described method (Bevilacqua et al, 1994). Three, 7, 10, 14, and $21 \mathrm{~d}$ old rats were studied. Carbachol in the presence of lithium stimulates ${ }^{3} \mathrm{H}$-CMP-PA accumulation throughout the cortex at all ages studied. In comparison labeled neurons responding to $t-A C P D$ in the presence of lithium were located exclusively in layer $V$ at P3 and P7, but were found labeled throughout the cortex at P10.

Given that glutamate and cholinergic agonist stimulation are both necessary but not sufficient for cortical plasticity to occur, and that muscarinic and mGluRs stimulation both induce a peak in PI turnover response during the same period of experience-dependent neocortical plasticity, PI derived second messengers signals might be involved in the regulation of the molecular mechanisms of neuronal plasticity. Furthermore, our results show the anatomical correlate of receptor-specific PI turnover activation, and indicate that specific agonist induced PI responses are age, and layer specific.

[Key words: phosphoinositide turnover, rat somatosensory cortex, development, critical period, autoradiography, metabotropic glutamate receptor]

Much work has been devoted to the phenomenological understanding of the processes that lead to the establishment of the neocortical structure (Rauschecker, 1991). It is well documented

\footnotetext{
Received Feb. 14, 1995; revised June 14, 1995; accepted July 17, 1995.

We thank Mr. Bob Jones and Mr Guy Pitt, Photography Unit, School of Molecular and Medical Biosciences, U.W.C.C., for expert photographic assistance. We also acknowledge Dr. Jim Ralphs and Mr. Tony Hayes from Anatomy Unit, School of Molecular and Medical Biosciences, U.W.C.C., for the use of image analysis system equipment and useful technical advice. P.R.L. is a Research Fellow of The Lister Institute of Preventive Medicine. This work was supported by a Project Grant from The Wellcome Trust to C.P.D. and P.R.L.

Correspondence should be addressed to Pedro R. Lowenstein, Molecular Medicine Unit, Department of Medicine, University of Manchester, School of Medicine, Stopford Building, Oxford Road, Manchester M13 9PT, UK.

Copyright (C) 1995 Society for Neuroscience 0270-6474/95/157916-13\$05.00/0
}

that the neocortex displays a higher susceptibility to experienceinduced synaptic modification during early stages of postnatal development (Hubel and Wiesel, 1970; Van der Loos and Woolsey, 1973; Blakemore and Van Sluyters, 1974; Woolsey and Wann, 1976; Cynader and Mitchell, 1980; Fox, 1992; Schlaggar et al., 1993; Fox and Zahs, 1994). Studies in the rat somatosensory cortex have shown the existence of a narrow period during early postnatal development during which the anatomical and functional structure of the neocortex is highly modifiable in response to changes in the afferent input from the peripheral sensory organs, and after which the cortical circuitry remains relatively unchanged in response to modifications in afferent input (Hubel and Wiesel, 1970; Blakemore and Van Sluyters, 1974; Cynader and Mitchell, 1980). This particular period of postnatal cortical development in mammals is known as the "critical" or "sensitive" period of neocortical development (Hubel and Wiesel, 1970; Fox, 1992; Fox and Zahs, 1994), and has also been exhaustively documented in the cat and primate visual cortex (Hubel and Wiesel, 1970; Blakemore and Van Sluyters, 1974; Cynader and Mitchell, 1980; Le Vay et al., 1980; Daw et al., 1992). Studies of the pathways involved in the regulation of this phenomenon indicate that three neurotransmitter systems are necessary for neocortical synaptic plasticity to proceed, namely: glutamate (Shaw et al., 1984; Kleinschmidt et al., 1987), ACh and noradrenaline (Bear and Singer, 1986).

In rat visual cortex, it has been shown that the critical period for dark rearing and monocular deprivation induced changes of visual cortical function, occurs between days $21-40$ of postnatal life (Fagiolini et al., 1994). The peák in glutamate induced PIturnover in rat cortex peaks at 1 week postnatal, and disappears around 35-40 d postnatal. Very recently the correlation of the critical period of cortical modifiability in response to external factors, and inducibility of long term potentiation (LTP) has been compared in the somatosensory and visual cortex. In somatosensory cortex LIP can be induced between days 3-7 postnatal, while in visual cortex it can be induced between days 14-21 (Crair and Malcnka, 1995; Kirkwood et al., 1995). Thus, LTP can be induced earlier in the somatosensory cortex, compared to the visual cortex.

Receptors for noradrenaline (Levitt and Moore, 1979; Morris et al., 1980), ACh (Cortés and Palacios, 1986; Spencer et al., 1986; Buckley et al., 1988; Levey et al., 1991), and glutamate (Stephens et al., 1991; Abe et al., 1992; Shigemoto et al., 1992, 1993) are present in the developing rat neocortex, and the expression of some of these receptors has been recently demon- 


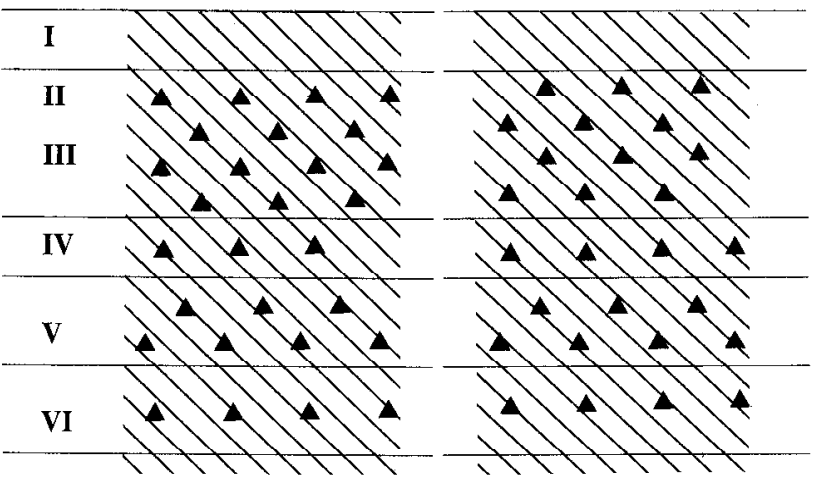

WM

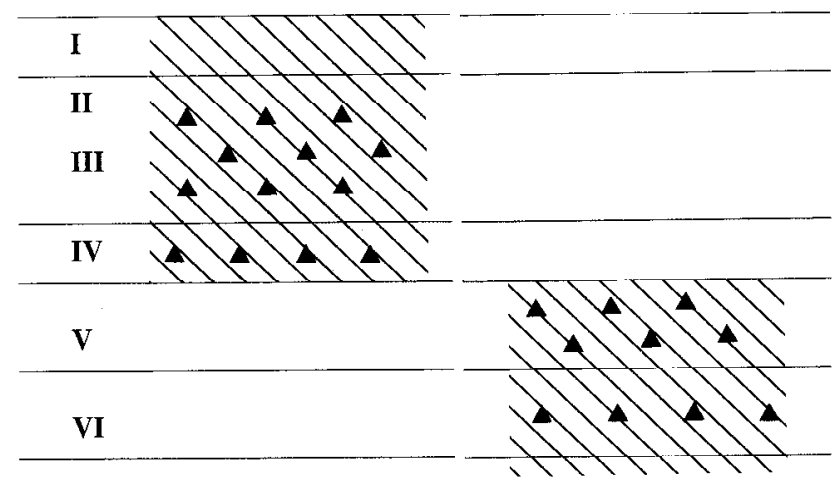

WM

C

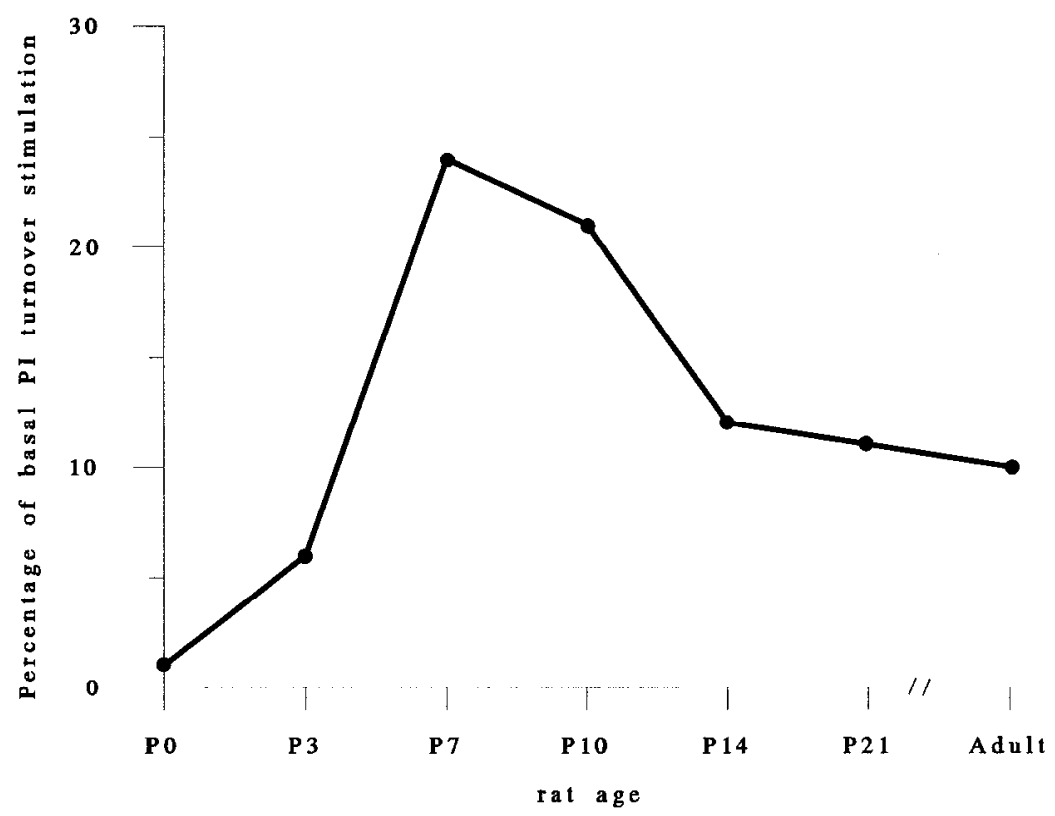

Figure 1. Schematic representation of the hypothetical anatomical substrates that could account for the neurotransmitter-induced peak in phosphoinositide detected biochemically during the development of neocortex. $A$, Different neurotransmitters induce labeling throughout all cortical layers. The peak of neocortical PI turnover results from the stimulation of neurons in all cortical layers by several neurotransmitters. $B$, Distinct agonists induce layer specific labeling. The peak of neocortical PI turnover results from the stimulation of neurons in different cortical layers by individual neurotransmitters. $C$, Schematic representation of the PI turnover peak detected biochemically by measuring incorporation of ${ }^{3} \mathrm{H}$-inositol into inositol polyphosphates after specific receptor stimulation. Roman numerals indicate cortical layers; WM, white matter; $\boldsymbol{\Delta}$, labeled neurons; the diagonal strip pattern represents neuropil labeling.

strated to be transient (Blue and Johnston, 1994). In addition noradrenaline, $\mathrm{ACh}$ and glutamate receptor stimulation increase PI-turnover in rat cortex preparations (Berridge et al., 1982; Gonzales and Crews, 1985; Nicoletti et al., 1986a,b; Balduini et al., 1991). Moreover, it has been shown that muscarinic and glutamatergic agonist stimulated PI-turnover is higher in neonate than in adult cortex (Dudek et al., 1989). Interestingly, a similar peak in PI response can be elicited in kitten neocortex by muscarinic and mGluRs stimulation, and this transient peak parallels the time window of the critical period of kitten visual cortex plasticity (Dudek and Bear, 1989). Therefore, it has been suggested that increased PI-turnover is directly implicated in the cellular mechanism that leads to neuronal neocortical plasticity
(Dudek and Bear, 1989; Bear and Dudek, 1991). If a certain threshold of neurotransmitter induced phosphoinositide turnover is necessary for neocortical maturation to proceed, two mechanisms could account for this transient peak (Fig. 1): either different neurotransmitters stimulate all layers simultaneously (Fig. $1 A$ ); or neurotransmitter stimulation is layer specific (Fig. 1B). Notice that both mechanisms could subserve a transient peak (Fig. 1C). Alternatively, a mixed mechanism could also occur.

However, the exact mechanisms by which activation of PI turnover via these neurotransmitter systems is affecting synaptic plasticity is not completely clarified. While it has been suggested that excitatory amino acid (EAA) receptor stimulation controls the magnitude of synaptic plasticity changes occurring in the 
neocortex, the catecholaminergic and noradrenergic systems appear to play a permissive role over EAA effects (Bear and Dudek, 1991). Nevertheless, there has been no information so far regarding which individual neurons or cortical layers respond with increased phosphoinositide turnover to each individual neurotransmitter.

In the present article, we report that mGluRs stimulation induces a specific transient phosphoinositide response mainly in layer $\mathrm{V}$ neocortical pyramidal neurons at P7 using a novel method recently described by us that allows to visualize which individual pyramidal neurons are activated after specific agonist receptor stimulation (Bevilacqua et al., 1994). By contrast, muscarinic receptor stimulation while also inducing a transient peak, labels pyramidal neurons throughout the cortex at all ages studied. Therefore, mGluR stimulation at early stages of neocortical development is specific for layer V. Furthermore, we propose that layer $\mathrm{V}$ pyramidal neurons play an important role in coordinating neocortical synaptic plasticity at early stages of rat postnatal cortical development.

\section{Materials and Methods}

Chemicals and reagents. Carbamylcholine chloride (carbachol), hydroxyurea, actinomycin D, myo-inositol, ribonuclease $\mathrm{A}$, and deoxyribonuclease I were obtained from Sigma. Lithium chloride, was purchased from Fisons, UK. Trans-dicarboxyl-ACPD [( \pm -1-aminocyclopentane-trans-1,3-dicarboxylic acid] (t-ACPD), was obtained from Tocris Neuramin, UK. Paraformaldehyde EM grade was obtained from Agar Scientific LTD, UK. Glutaraldehyde $25 \%$ EM grade was purchased from Taab Laboratories, UK. Osmium tetroxide was obtained from Johnson Matthey PLC, UK. Proteins were measured by BCA Protein Assay Reagent Kit, Pierce, USA. Dowex $1 \times 8$ resin $(200-400$ mesh, chloride form) was obtained from Sigma,U.K. $5^{\prime}-{ }^{3} \mathrm{H}$-cytidine $(20.85 \mathrm{Ci} /$ $\mathrm{mmol})$, and D-myo-2- ${ }^{3} \mathrm{H}$-inositol $(23.45 \mathrm{Ci} / \mathrm{mmol})$ were purchased from New England Nuclear, U.K.

Animals and tissue slice preparation. Wistar rats were from an inhouse bred colony originally ohtained from Charles River, U.K. The age of the animals, either sex, was determined by controlling the date and hour of birth $\pm 12 \mathrm{hr}$. The day in which the animal was born was considered as postnatal day 1 (P1). Animals were sacrificed by cervical dislocation followed by immediate decapitation; brains were then removed and dissected on ice. The tissue was sliced coronally at $350 \mu \mathrm{m}$. Somatosensory cortex slices were oblained by sectioning apart the frontal and occipital lobes by coronal incisions made approximately $2 \mathrm{~mm}$ anterior to bregma and $4 \mathrm{~mm}$ posterior to bregma, respectively, followed by a transverse section at the level of the rhinal fissure. The remaining cortex was then carefully separated from the underlying tissue with spatulas and placed onto a flat surface. A final incision, approximately $2 \mathrm{~mm}$ lateral to the mid-line was performed in order to remove the forelimb, hindlimb somatosensory regions and cingulate cortical areas.

${ }^{3} \mathrm{H}$-PtdCMP accumulation for morphological studies. ${ }^{3} \mathrm{H}-\mathrm{PtdCMP}$ accumulation for morphological studies was performed as in Bevilacqua et al. (1994). Briefly, after dissection slices were recovered in KrebsRinger bicarbonate buffer (KRB), $\mathrm{pH} 7.4$ at $37^{\circ} \mathrm{C}$, gassed periodically with $\mathrm{O}_{2} / \mathrm{CO}_{2}, 95 \% / 5 \%$, respectively, with the following composition: $\mathrm{NaCl}, 118 \mathrm{~mm} ; \mathrm{NaHCO}_{3}, 25 \mathrm{~mm} ; \mathrm{KCl}, 4.7 \mathrm{~mm} ; \mathrm{MgSO}_{4} .7 \mathrm{H}_{2} \mathrm{O}, 1.2 \mathrm{~mm}$; $\mathrm{CaCl}_{2} \cdot \mathrm{H}_{2} \mathrm{O}, 1.3 \mathrm{~mm} ; \mathrm{KH}_{2} \mathrm{PO}_{4}, 1.2$ inm; glucose, $12 \mathrm{~mm}$. Tissue slices were left to recover for $60 \mathrm{~min}$. The buffer was periodically gassed with $\mathrm{O}_{2} / \mathrm{CO}_{2}(95 \% / 5 \%)$. Slices were then washed once in fresh $\mathrm{KRB}$ and transferred individually or in groups into $5 \mathrm{ml}$ flat bottomed plastic vial insert tubes containing $3.0 \mu \mathrm{Ci}$ of ${ }^{3} \mathrm{H}$-cytidine in $300 \mu \mathrm{l}$ final volume of KRB. Inhibitors of nucleic acid synthesis were added to the incubation buffer at this step, simultaneously with ${ }^{3} \mathrm{H}$-cytidine at the following concentration: hydroxyurea, $50 \mathrm{~mm}$ and of actinomycin $\mathrm{D}, 1 \mu \mathrm{g} /$ $\mathrm{ml}$. Slices were allowed to incorporate the radioactive lahel for $30 \mathrm{~min}$. in a gently shaking bath, at $37^{\circ} \mathrm{C}$. Drugs were added after $30 \mathrm{~min}$ of labeling at the following concentrations, $\mathrm{LiCl}, 20 \mathrm{~mm}$; carbachol, $2 \mathrm{mM}$; $t$-ACPD; $0.2 \mathrm{~mm}$, samples were then incubated for further $30 \mathrm{~min}$. To stop the reaction, the incubation medium was aspirated and slices were washed several times with ice cold KRB. The slices were then fixed in $2 \%$ paraformaldehyde, $2.5 \%$ glutaraldehyde in $0.1 \mathrm{M}$ PBS ( $\mathrm{pH} 7.4)$ fur $30 \mathrm{~min}$, and postfixed in $1 \%$ osmium tetroxide $\left(\mathrm{OsO}_{4}\right)$ in $0.1 \mathrm{M}$ PBS
( $\mathrm{pH}$ 7.4) further $30 \mathrm{~min}$. Afterwards, slices were dehydrated in increasing concentrations of ethanol with a final step in propylene oxide. Infiltration in Durcupan resin was performed overnight. The next day, slices were flat-embedded on glass slides in fresh Durcupan resin and left to polymerized at $56^{\circ} \mathrm{C}$ during $48 \mathrm{hr}$. The coverslips were then carefully removed from the polymerized layer of resin. Small pieces of resin containing whole hippocampal or neocortical slices were reembedded in Durcupan resin blocks. Semithin sections ( $1 \mu \mathrm{m}$ thick) were cut on a Reichert-Jung Ultracut ultramicrotome and placed on acid cleaned slides. Slides were then dried on a hot plate. Coating with Ilford K5 autoradiographic emulsion (1:2 in $2 \%$ glycerol in distilled water) was performed under Ilford 904 safelight. Sections were exposed for 5-7 d at $4^{\circ} \mathrm{C}$. Developing of the coated slides was performed with Kodak D19 for $4 \mathrm{~min}$ at $16^{\circ} \mathrm{C}$ and the slides were then fixed in $30 \%$ aqueous sodium thiosulfate for $8 \mathrm{~min} 16^{\circ} \mathrm{C}$. Sections were counterstained with Richardson's Blue (Azure II/ methylene blue/ borax $1 \%$ each $w / v$ in distilled water), dehydrated and mounted with DPX (BDH, UK). Photomicrographs were obtained using an Olympus Vanox AH-2 photo microscope in bright- and dark-field utilizing Ilford FP4 film for bright-field micrographs and Kodak Technical Pan 2415, for dark-field micrographs. Due to a number of factors (e.g., the use of $1 \mu \mathrm{m}$ semithin resin sections, the regular disposition of apical pyramidal cell dendrites versus the random distribution of nonpyramidal cell dendrites, absence of cell type specific counterstains used), morphologically, we can only reliably identify the accumulation of ${ }^{3} \mathrm{H}-\mathrm{PtdCMP}$ within neocortical pyramidal cells (Bevilacqua et al., 1994).

Assay of ${ }^{3} \mathrm{H}$-phosphatidyl CMP accumulation and ${ }^{3} \mathrm{H}$-inositol lipid hydrolysis. For biochemical measurements of agonist neurotransmitterinduced phoshoinositide turnover $350 \times 350 \mu \mathrm{m}$ cross-chopped slices were used instead of the coronal slices used for morphological studies. Stimulation of phosphoinositide turnover was performed as for morphological studies (see above). The following modifications were introduced; 5' ${ }^{3} \mathrm{H}$-cytidine and $\mathrm{D}-m y o-2-{ }^{3} \mathrm{H}$-inositol were used both at 0.33 $\mu \mathrm{Ci} / 100 \mu \mathrm{l}$ of KRB. All the other regents including agonists were used at the same concentration. The reaction was tcrminated by addition of ice-cold trichloroacetic acid (TCA) to a final concentration of $0.5 \mathrm{M}$, the samples were then left to in ice for $20 \mathrm{~min}$ before the analysis of ${ }^{3} \mathrm{H}$-PtdCMP or ${ }^{3} \mathrm{H}$-inositol phosphates.

${ }^{3} \mathrm{H}$-PtdCMP measurement. The acid extracted pellet was then washed once with an aqueous solution of TCA $(5 \% \mathrm{w} / \mathrm{v})$ containing $1 \mathrm{~mm}$ EDTA and once in ice cold distilled water. To each sample, $750 \mu l$ of methanol/chloroform/ $12 \mathrm{M} \mathrm{HCl}(80: 40: 1$ by vol) were added. Samples were then allowed to stand for further $20 \mathrm{~min}$ until the addition of 250 $\mu l$ of chloroform. The solvent mixture from each tube was then collected in a separate vial and phases were split after the addition of 450 $\mu 1$ of $0.1 \mathrm{M} \mathrm{HCl}$ by centrifugation for $2 \mathrm{~min}$ at $2000 \mathrm{r.p.m}$. Aliquots $(200 \mu \mathrm{l})$ from the lower, lipid containing phase (chloroform soluble fraction) were placed in counting vials, and the solvent was left to evaporate. Scintillation cocktail (Ulinila Gold, Packard, UK), was then added and samples were counted.

${ }^{3} \mathrm{H}$-Inositol phosphate analysis. Samples $(0.4 \mathrm{ml})$ of supernatant were mixed $0.1 \mathrm{ml}$ of $10 \mathrm{~mm}$ EDTA $(\mathrm{pH} 7.5$ with $\mathrm{NaOH}$ ), and $0.2 \mathrm{ml}$ of 1,1,2-trichlotrifluororoetane/tri-n-octylamine, (1:1, v/v) to remove acid; the mixture was vortexed and spun at 2000 r.p.m to help phase separation. Aliquots of the upper phase $(200 \mu \mathrm{l})$ were then analyzed on Dowex $1 \times 8$ chromatography resin columns. ${ }^{3} \mathrm{H}$-inositol phosphates and ${ }^{3} \mathrm{H}$-glycerophosphoinositol phosphates were then separated and counted as described elsewhere (Batty et al., 1985; Simpson et al., 1987).

Quantification of autoradiographic labeling in cortical tissue slice. The same slides wcre used to obtain photomicrographs and to quantify the density of grains present over different components of the tissue. To this end the Quantimet 500 + Imaging Processing and Analysis System, Leica, Cambridge, U.K. was used. The area occupied by the silver grains (grain area) was assessed against the nonlabeled background tissue, within the perimeter of a given cellular or neuropil area of tissue. In order to calculate the area occupied by each cell, the cell perimeter was outlined and the area included within the line drawn was computed.

Statistical analysis of data. Two measurements were used to calculate the density of silver grains over neuronal bodies and neuropil: (1) The total amount of silver grains, calculated as the area occupied by the

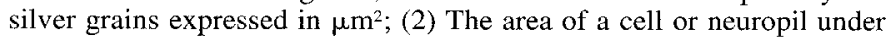
study also expressed in $\mu \mathrm{m}^{2}$. The area occupied by neuronal cell bodies was determined by outlining manually each cell perimeter on the computer screen and the enclosed area was then calculated (cell area, CA). In the case of the neuropil, the area under study was outlined on the 
Table 1. Summary of results obtained from analyzing the density of silver grains over neuronal bodies and neuropil in two or three different experiments performed at each age studied

\begin{tabular}{|c|c|c|c|c|c|c|}
\hline \multirow[b]{3}{*}{ Layer } & \multicolumn{6}{|l|}{ Age } \\
\hline & $3 \mathrm{~d}$ & & $7 \mathrm{~d}$ & & $10 \mathrm{~d}$ & \\
\hline & $\overline{\text { Cells }}$ & Neupl & Cells & Neupl & $\overline{\text { Cells }}$ & Neupl \\
\hline
\end{tabular}

\begin{tabular}{lllllll}
\hline$t$-ACPD & & & & & & \\
I & - & $0: 2$ & - & $0: 3$ & - & $0: 3$ \\
II/III & $0: 2$ & - & $0: 3$ & $0: 3$ & $2: 3$ & $3: 3$ \\
V & $2: 2$ & $0: 2$ & $3: 3$ & $0: 3$ & $1: 3$ & $3: 3$ \\
VI & $1: 2$ & $0: 2$ & $0: 3$ & $0: 3$ & $2: 3$ & $2: 3$ \\
Carbachol & & & & & & \\
I & - & $1: 2$ & - & $3: 3$ & - & $2: 3$ \\
II/III & $1: 2$ & - & $3: 3$ & $3: 3$ & $2: 3$ & $3: 3$ \\
V & $2: 2$ & $1: 2^{*}$ & $3: 3$ & $2: 3 \#$ & $2: 3$ & $3: 3$ \\
VI & $1: 2$ & $1: 2$ & $3: 3$ & $3: 3$ & $3: 3$ & $2: 3$
\end{tabular}

Each fraction shown represents the ratio between positive experiments against the total number of experiments quantified for each age, and for both neurons and neuropil (neupl). For example, 0:3 means that in none out of three experiments evaluated did the density of grains differ from controls as evaluated by Student's $t$ test for paired samples $(15) ; 2: 3$ means that in two out of three experiments evaluated, the density of silver grains differed from lithium controls, etc. Differences were considered statistically significant when $p<0.02$.

* The negative experiment has a borderline result, $p<0.025$.

\# The negative experiment has a borderline result, $p<0.058$

computer screen excluding cell bodies (neuropil area, NA). The density of grains was then calculated as the ratio (R) between the grain area (GA) over the cell or neuropil area, according to the equation $R_{\text {neuron }}=$ $\mathrm{GA} / \mathrm{CA}$ or $R_{\text {neuropil }}=\mathrm{GA} / \mathrm{NA}$. As $R$ values were usually below 0 , they were multiplied by 100 in order to facilitate the understanding of the quantification. Thus, $R$ values represent the number of grains contained within a cell body or a given area of neuropil. Two to three experiments from each age considered were evaluated. In each experiment three different conditions were analyzed: lithium- (control), $t$-ACPD plus lithium-, and carbachol plus lithium-induced labeling. The density of grains was counted for neurons in cortical layers II-III (or cortical plate in P3 old animals); V and VI, and for the neuropil in areas I, II-III (CP), V and VI at P3, P7, and P10. The mean of $10 R$ values $(X R)$ from each cortical layer was calculated. The mean for each layer was then compared to the corresponding layer in lithium controls from the same ex- periment. Significance was calculated by Student's $t$ test for paired samples and significance was considered as $P^{*}<0.02$. A layer was considered labeled when its $X R$ value was significantly higher than the $X R$ value in lithium controls. Therefore labeling was considered negative when the value was equal or lower than the value in lithium controls (Tables 1, 2).

\section{Results}

\section{Morphological studies}

The great majority of the labeled cells were pyramidal-like neurons according to the shape of the cellular body and the main apical dendrite. With the methodology used in the present study, it was not possible to detect labeling in small neurons (i.e., layer I, IV ncurons) or glial cells. Thus, the results reported in the following paragraph refer to pyramidal-like neurons in layers II, III, V, and VI. Labeling was occasionally seen in non-pyramidal like cells. Nevertheless, in the case of cortical layer I, due to the low density of cell bodies, the density of silver grains in the neuropil could be quantified independently and changes in the density of silver grains in this layer are reported for the different ages studied.

At P3 the labeling detected in individual cortical layers was agonist-dependent. Control slices, incubated with lithium $20 \mathrm{~mm}$ alone, showed a light labeling distributed homogeneously throughout the cortex (Fig. $2 a$ ) and at high power magnification, few grains were observed over the perikarya and dendrites of neurons in the cortical plate (Fig. 2b), layer V (Fig. 2c) and layer VI (Fig. $2 d$ ). By contrast, Carbachol $2 \mathrm{~mm}$ in the presence of lithium $20 \mathrm{~mm}$ (Fig. $2 i-l$ ), induced a strong labeling that was distributed homogeneously throughout the cortex (Fig. 2i) when compared to controls. Neurons in the cortical plate (Fig. $2 j$ ), layer V (Fig. $2 k$ ) and layer VI (Fig. $2 l$ ) displayed a dense silver grain accumulation in comparison to lithium alone incubations (Fig. $2 a-d$ ). Labeling induced by $t$-ACPD $0.2 \mathrm{~mm}$ in the presence of lithium $20 \mathrm{~mm}$ was limited to layer $\mathrm{V}$ (Fig. $2 e, g$ ). The quantitation of the labeling of the cortical plate induced by mGluRs-agonist stimulation showed no statistical difference to the labeling induced by lithium alone (see following section). At this age the neuropil was only found labeled after carbachol stimulation in the presence of lithium (Tables 1, 2).

Table 2. Semiquantification of the density of silver grains over neuronal cell bodies in layers II-III, V, and VI, and neuropil of cortical layers I, II-III, V, and VI

\begin{tabular}{|c|c|c|c|c|c|c|}
\hline \multirow[b]{3}{*}{ Layer } & \multicolumn{6}{|l|}{ Age } \\
\hline & \multicolumn{2}{|l|}{$3 d$} & \multicolumn{2}{|l|}{$7 \mathrm{~d}$} & \multicolumn{2}{|l|}{$10 \mathrm{~d}$} \\
\hline & Neurons & Neuropil & Neurons & Neuropil & Neurons & Neuropil \\
\hline \multicolumn{7}{|l|}{$t$-ACPD } \\
\hline I & - & $0.8 \pm 0.1$ & - & $1.1 \pm 0.3$ & - & $2.1 \pm 0.3$ \\
\hline II/III & $6.99 \pm 0.8$ & - & $8.62 \pm 1.3$ & $1.5 \pm 0.3$ & $15.7 \pm 1.1^{a}$ & $4.6 \pm 0.4^{i}$ \\
\hline $\mathrm{V}$ & $13.4 \pm 1.3^{3}$ & $0.9 \pm 0.1$ & $25.7 \pm 2.0^{a}$ & $2.3 \pm 0.6$ & $24.7 \pm 2.1^{a}$ & $4.6 \pm 0.4^{g}$ \\
\hline VI & $6.75 \pm 1.3$ & $0.7 \pm 0.1$ & $10.5 \pm 1.1$ & $1.4 \pm 0.6$ & $12.3 \pm 1.1^{\circ}$ & $2.2 \pm 0.2$ \\
\hline Carbachol & & & & & & $i$ \\
\hline I & $\ldots$ & $0.6 \pm 0.1$ & - & $4.3 \pm 0.4^{a}$ & - & $4.4 \pm 0.6^{g}$ \\
\hline II/III & $9.71 \pm 1.9$ & - & $21.9 \pm 2.3^{a}$ & $4.2 \pm 0.4^{\mathrm{b}}$ & $20.2 \pm 1.5^{a}$ & $4.9 \pm 0.5^{g}$ \\
\hline V & $24.9 \pm 3.0^{b}$ & $1.3 \pm 0.1$ & $34.2 \pm 1.9^{a}$ & $4.1 \pm 0.5^{k}$ & $16.5 \pm 1.6^{a}$ & $5.4 \pm 0.7^{h}$ \\
\hline VI & $10.1 \pm 1.0$ & $1.0 \pm 0.1$ & $25.8 \pm 2.0^{a}$ & $4.1 \pm 0.5$ & $19.2 \pm 1.6^{a}$ & $1.9 \pm 0.3$ \\
\hline
\end{tabular}

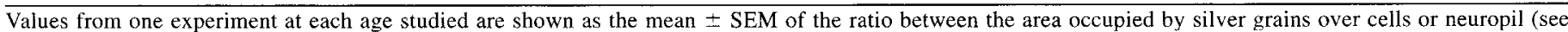

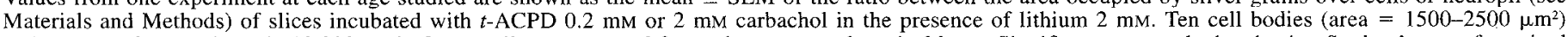

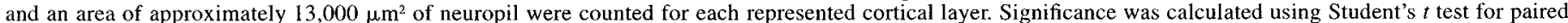

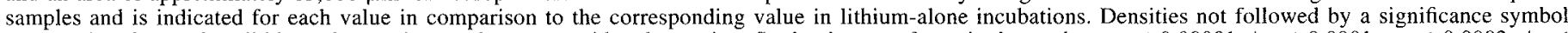

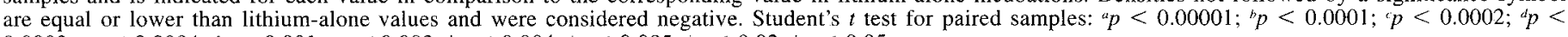
$0.0003 ;{ }^{p} p<0.0004 ;{ }^{\prime} p<0.001 ;{ }^{p} p<0.003 ;{ }^{h} p<0.004 ;{ }^{i} p<0.005 ;{ }^{p} p<0.02 ;{ }^{k} p<0.05$. 

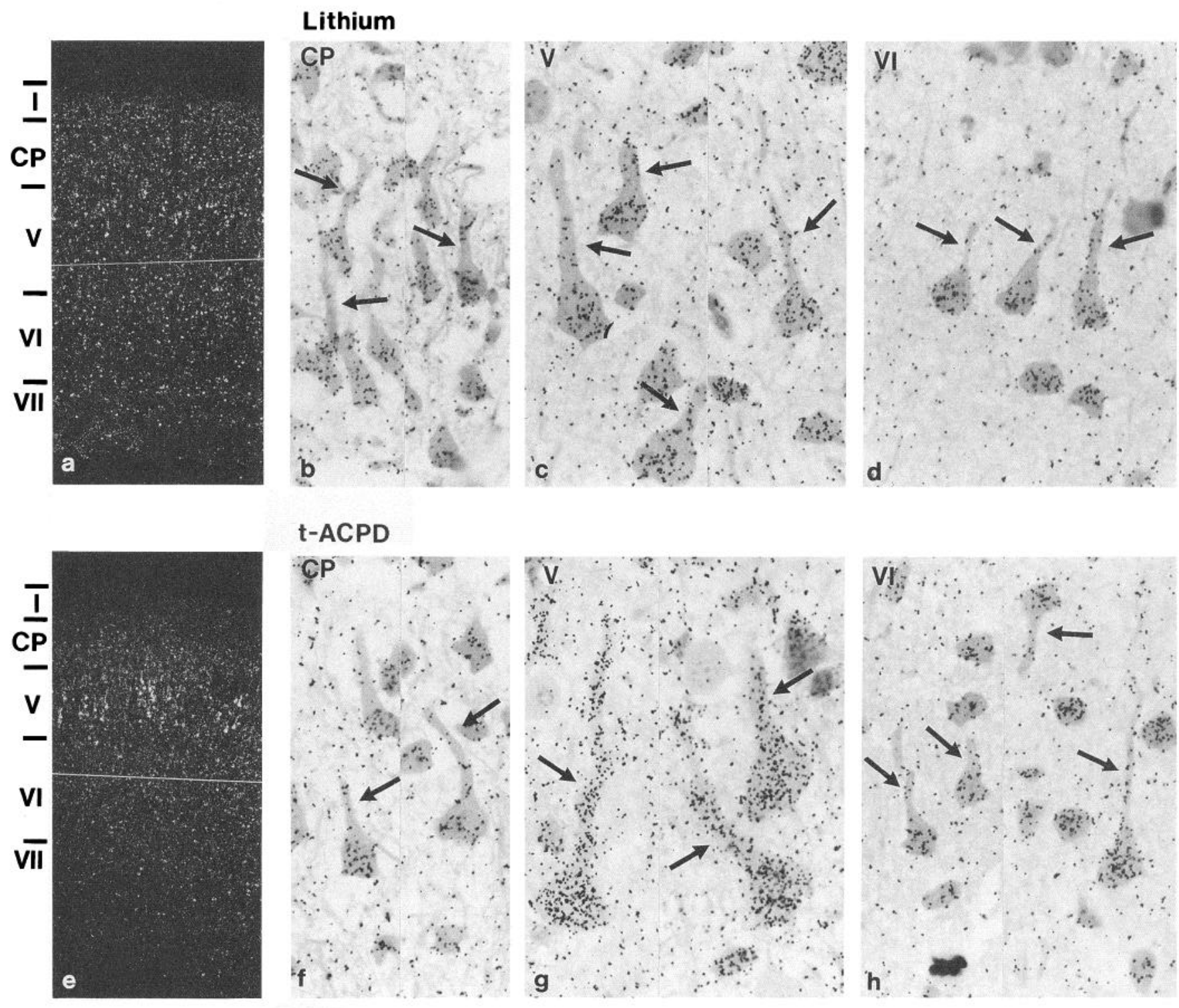

\section{t-ACPD}
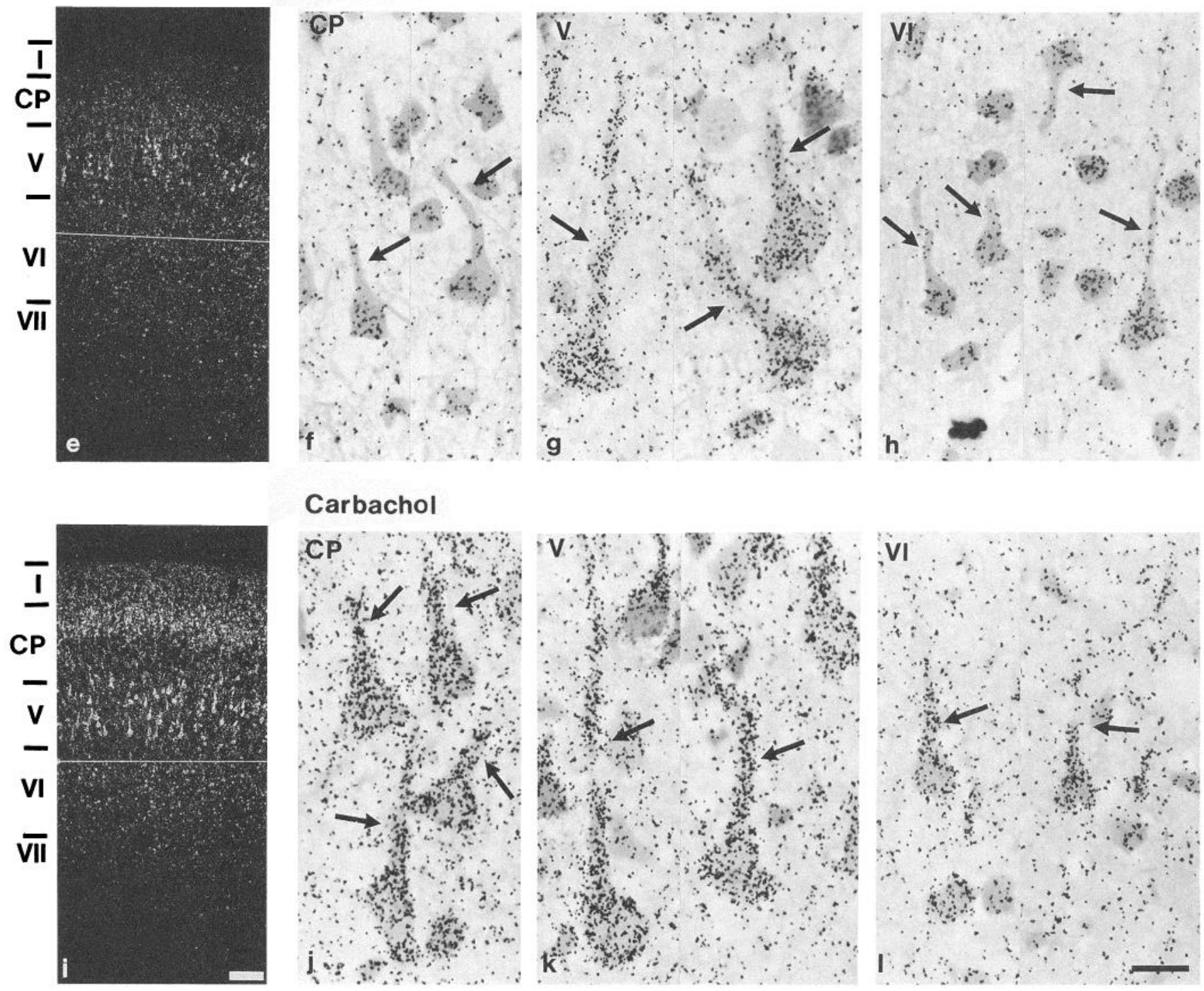

\section{Carbachol}
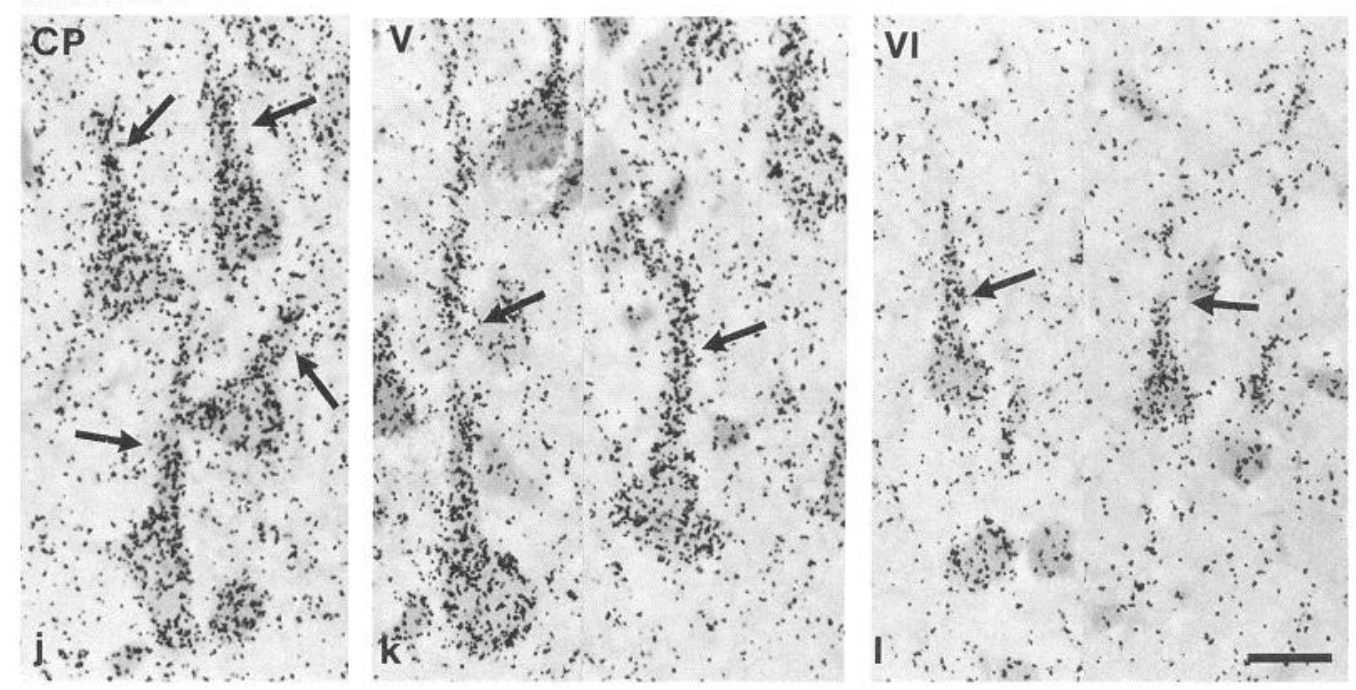

Figure 2. Composite microphotograph of autoradiographic imaging of agonist-induced ${ }^{3} \mathrm{H}-\mathrm{PtdCMP}$ accumulation in rat somatosensory cortex at P3. Lithium-, carbachol-, and $t$-ACPD-induced accumulation of ${ }^{3} \mathrm{H}$-phosphatidyl CMP in rat somatosensory cortex at $3 \mathrm{~d}$ postnatally. This figure 
The labeling pattern changed dramatically at P7 (Fig. 3). The silver grain accumulation induced by carbachol $2 \mathrm{~mm}$ in the presence of lithium $20 \mathrm{~mm}$ (Fig. $3 i, j-l$ ) was very strong in all layers compared to lithium controls. Cellular bodies and dendrites of pyramidal-like neurons became densely packed with silver grains in layer II-III (Fig. 3j), V (Fig. 3k), and layer VI (Fig. $3 l$ ). At the same age, $t$-ACPD $0.2 \mathrm{~mm}$ in the presence of lithium $20 \mathrm{~mm}$, induccd a strong labeling limited to ncurons in layer $\mathrm{V}$ of the cortex (Fig. $3 e, g$ ), while cell bodies in the remaining layers did not show a labeling stronger than that induced by lithium alone. At this age the quantification of grains present in the neuropil revealed a strong labeling in all layers studied after carbachol stimulation. Remarkably, $t$-ACPD stimulation of neuronal labeling was significant, however it did not induce a statistically significant labeling of the neuropil when compared to lithium alone incubated slices (Tables 1,2).

At P10, lithium incubated cortical slices (Fig. $4 a, b-d$ ) showed a labeling similar to that observed at P7 both in neurons and neuropil. At this age carbachol induced a strong labeling in all cortical layers compared with lithium alone incubated slices (Fig. 4i,j-k). Interestingly, at P10, $t$-ACPD in the presence of lithium, stimulated labeling in layers II-III, and VI of the neocortex (Fig. $4 e, f-h$ ) in addition to layer V. Importantly, at this age $t$-ACPD in the presence of lithium also induced a statisti- cally significant labeling of the neuropil of layers II-III, V, and VI but not layer I (Tables 1, 2).

At P14 the labeling obtained with all the agonists used was very low. Lightly labeled neurons could be observed in all cortical layers in slices incubated with carbachol in the presence of lithium. No layer specific pattern of labeling could be recognised for slices incubated with $t$-ACPD in the presence of lithium. At this age the neuropil showed a diffuse and sparse labeling throughout the cortex for all the agonists (data not shown).

Stimulation of somatosensory cortex slices in the presence of lithium at P21 induced poor labeling as evaluated by morphology. Only in carbachol stimulated slices were some cells found to be labeled.

The absence of nuclear staining observed in labeled cells (for example, in Figure $3 b, y, k, l$ ), confirms the effectiveness of the treatment used to reduce the labeling of nucleic acids by ${ }^{3} \mathrm{H}$ cytidine.

\section{Semiquantitative analysis of silver grains present over neuronal bodies and neuropil}

Analysis of the density of silver grains over cell somata and dendrites of neurons of layers II-III, V, and VI, and neuropil of layers I, II-III, V, and VI was performed at P3, P7, and P10 by using a Quantimet $500+$ image analysis system (Leica, Cam-

\title{
$\leftarrow$
}

shows dark- $(a, e, i)$ and bright-field $(b-d, f-h, j-l)$ images of $\mathrm{P} 3$ rat somatosensory cortex slices incubated with lithium 3 mM alone $(a-d) ; t$-ACPD in the presence of lithium $3 \mathrm{~mm}(e-h)$, or carbachol $2 \mathrm{~mm}$ in the presence of lithium $3 \mathrm{~mm}(i-l)$. After incubation with lithium alone the cortex showed a light labeling $(a)$. High power magnification of pyramidal neurons in CP $(b), \mathrm{V}(c)$, and VI $(d)$ revealed the presence of sparse grains over the perikarya and dendrites. After stimulation with $t$-ACPD in the presence of lithium, labeling was observed in layer $\mathrm{V}(e)$. At high magnification, pyramidal neurons in layer $V(g)$ demonstrated the presence of heavy labeling over cell bodies and main dendritic processes; however, pyramidal neurons in the $\mathrm{CP}(f)$ and VI $(h)$ did not show a significant difference in their labeling when compared to neurons incubated with lithium alone (see quantification in Tables 1 and 2). Stimulation with carbachol $2 \mathrm{~mm}$ in the presence of lithium, displayed a strong labeling throughout the cortex $(i)$. High magnification photomicrographs showed a much higher density of grains over cell bodies and dendrites of pyramidal neurons in $\mathrm{CP}(j), \mathrm{V}(k)$, and VI $(l)$. Notice the labeling of the neuropil in all layers in carbachol stimulated cells $(j-l)$. However, neuropil labeling was not statistically different from lithium alone incubated slices after $t$-ACPD stimulation (for quantification, see Tables 6 and 7). Arrows indicate dendrites. Scale bar in $i, 100 \mu \mathrm{m}$; scale bar in $l, 10 \mu \mathrm{m}$.

\begin{abstract}
Figure 3. Composite microphotograph of autoradiographic imaging of agonist-induced ${ }^{3} \mathrm{H}-\mathrm{PtdCMP}$ accumulation in rat somatosensory cortex at P7. Lithium-, carbachol-, $t$-ACPD-induced accumulation of ${ }^{3} \mathrm{H}$-phosphatidyl CMP in rat somatosensory cortex at $7 \mathrm{~d}$ postnatally. This figure shows dark- $(a, e, i)$ and bright-field $(b-d, f-h, j-l)$ images of P7 rat somatosensory cortex slices incubated with lithium $3 \mathrm{~mm}$ alone $(a-d)$; $t$ - ACPD in the presence of lithium $3 \mathrm{~mm}(e-h)$, or carbachol $2 \mathrm{~mm}$ in the presence of lithium $3 \mathrm{~mm}(i-l)$. After incubation with lithium alone the cortex showed a light labeling $(a)$. High power magnification of pyramidal neurons in layers II-III $(b)$, V $(c)$, and VI $(d)$ revealed a homogeneous labeling of the neurons in all layers. After stimulation with t-ACPD in the presence of lithium, labeling was predominantly observed in layer $V(e)$. At high magnification, pyramidal neurons in layer V $(g)$ demonstrated the presence of a very heavy labeling over cell bodies and main dendrites; however, quantification of grains present in pyramidal neurons of layers II-III $(f)$ and VI $(h)$, and in the neuropil of all layers considered did not show a significant difference in their labeling when compared to neurons incubated with lithium alone (Tables 1,2). Stimulation with carbachol 2 mm in the presence of lithium, displayed a strong labeling throughout the cortex $(i)$. High magnification photomicrographs showed a much higher density of grains over cell bodies and dendrites of pyramidal neurons in layers II-III $(j), \mathrm{V}(k)$, and VI $(l)$. The labeling was also observed in the neuropil of all layers $(j-l)$, (Tables 1,2). Treatment with inhibitors of nucleic acid synthesis (see Materials and Methods) reduced the staining over the nuclear area (seen more clearly in $b, c, g, k, l$ ). Cortical layering is indicated by roman numbers on the left margin of the figure. Arrows indicate dendrites. Scale bar in $i, 100 \mu \mathrm{m}$; scale bar in $l, 10 \mu \mathrm{m}$.

Figure 4. Composite microphotograph of autoradiographic imaging of agonist-induced ${ }^{3} \mathrm{H}-\mathrm{PtdCMP}$ accumulation in rat somatosensory cortex at P10. Lithium-, carbachol-, and $t$-ACPD-induced accumulation of ${ }^{3} \mathrm{H}$-phosphatidyl CMP in rat somatosensory cortex at $10 \mathrm{~d}$ postnatally. This figure shows dark- $(a, \varepsilon, i)$ and bright-ficld $(b-d, f-h, j-l)$ images of P10 rat somatosensory cortex slices incubated with lithium 3 mM alone (a $d$ ); $t$-ACPD in the presence of lithium $3 \mathrm{~mm}(e-h)$, or carbachol $2 \mathrm{~mm}$ in the presence of lithium $3 \mathrm{~mm}(i-l)$. After incubation with lithium alone the cortex showed a light labeling $(a)$. High power magnification of pyramidal neurons in layers II-III $(b)$, V $(c)$, and VI $(d)$ revealed the presence of a homogeneous number of grains over the perikarya and dendrites. After stimulation with $t$-ACPD in the presence of lithiun, the labeling was statistically greater than in lithium alone incubated slices in all layers $(e)$. At high magnification, pyramidal neurons in all layers demonstrated the presence of a heavier labeling over cell bodies and main dendrites, quantitation of silver grains present over neuropil also revealed this to be higher in $t$-ACPD stimulated samples than lithium alone incubations (Tables 1,2). Stimulation with carbachol 2 mm in the presence of lithium, displayed a strong labeling throughout the cortex (i). High magnification photomicrographs showed a much higher density of grains over cell bodies and dendrites of pyramidal neurons in layers II-III $(j), \mathrm{V}(k)$, and VI $(l)$. Treatment with inhibitors of nucleic acid synthesis (see Materials and Methods) reduced the staining over the nuclear area (seen more clearly in $f-h, j-l$ ). Cortical layering is indicated by roman numbers on the left margin of the figure. Arrows indicate dendrites. Scale bar in $i, 100 \mu \mathrm{m}$; scale bar in $l, 10 \mu \mathrm{m}$.
\end{abstract}




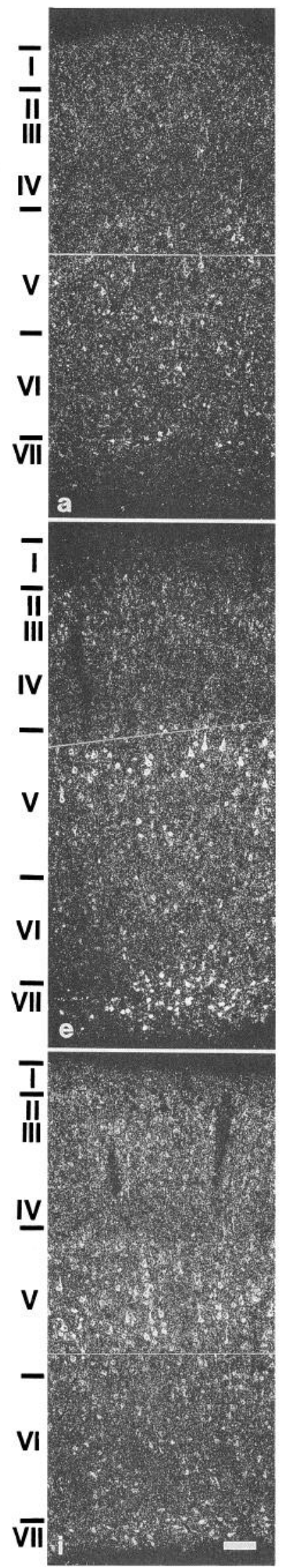

\section{Lithium}

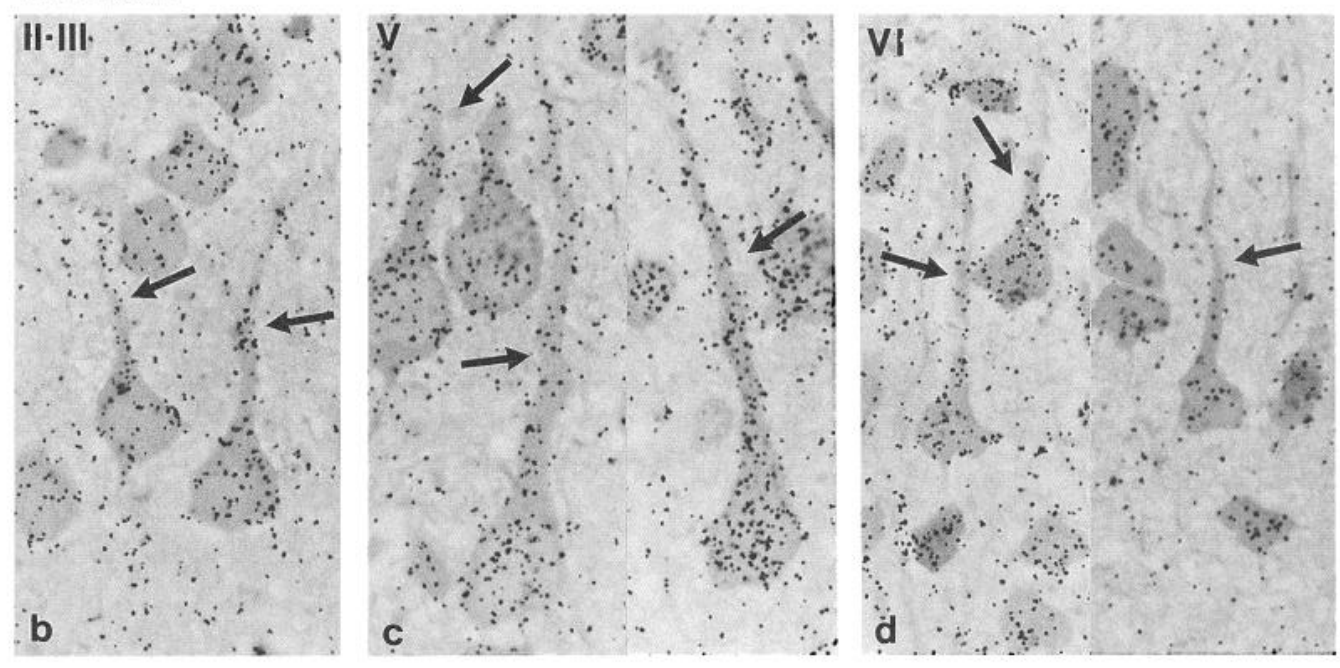

\section{t-ACPD}
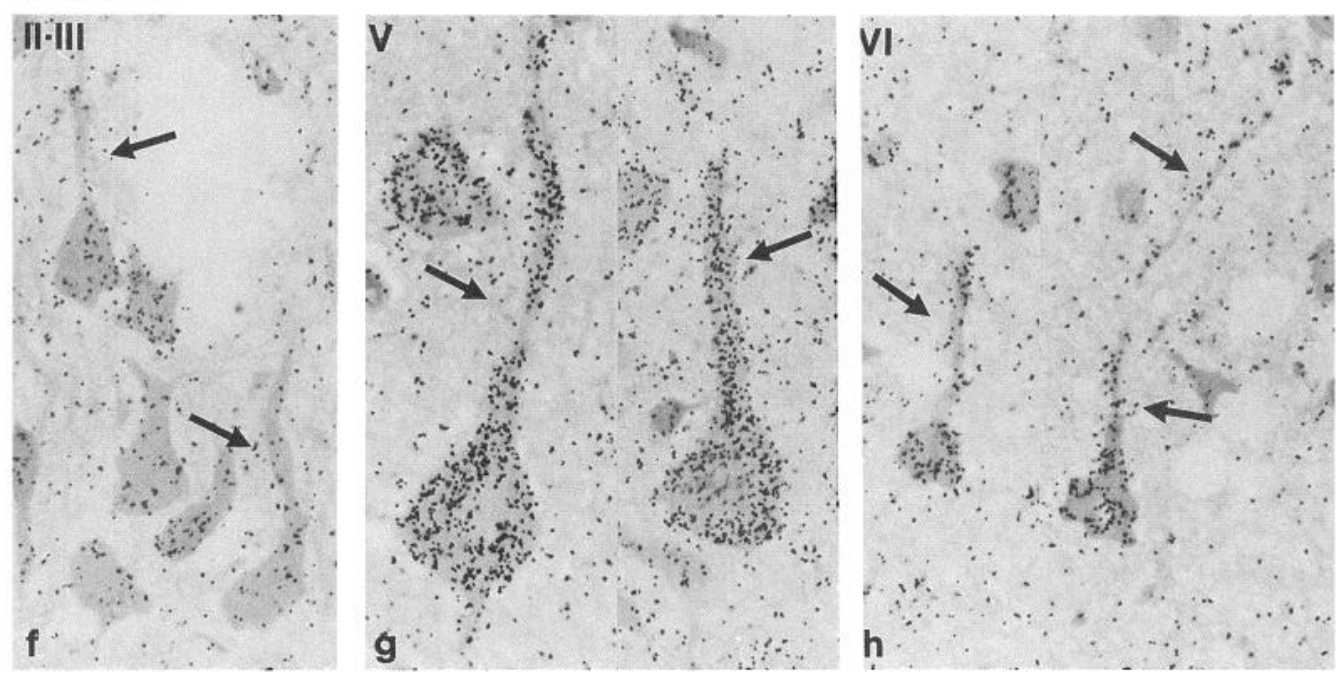

\section{Carbachol}

unty
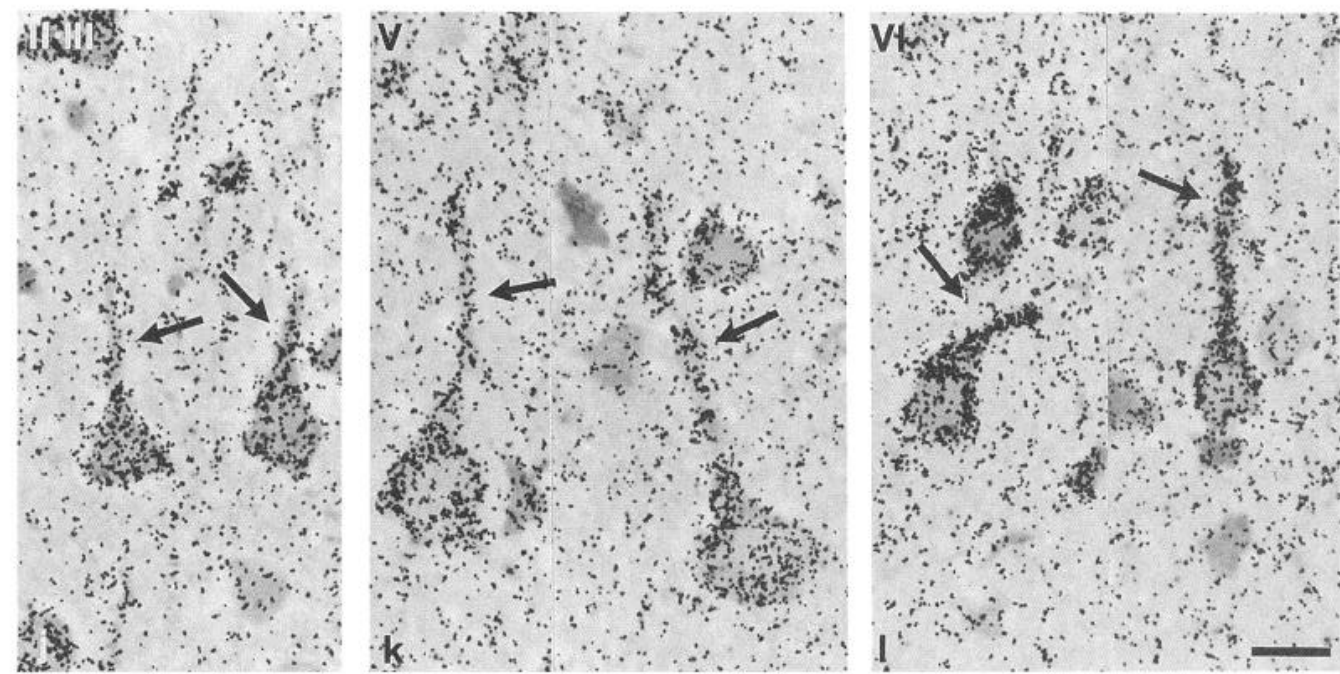

Figure 3. 


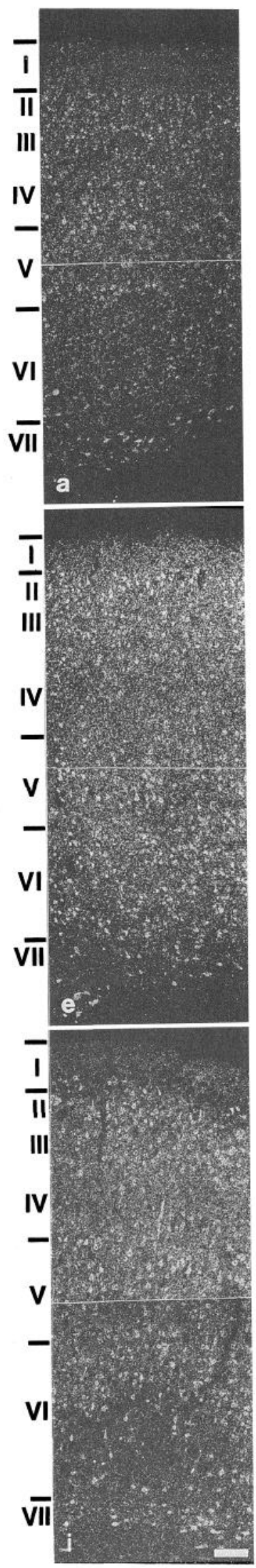

\section{Lithium}
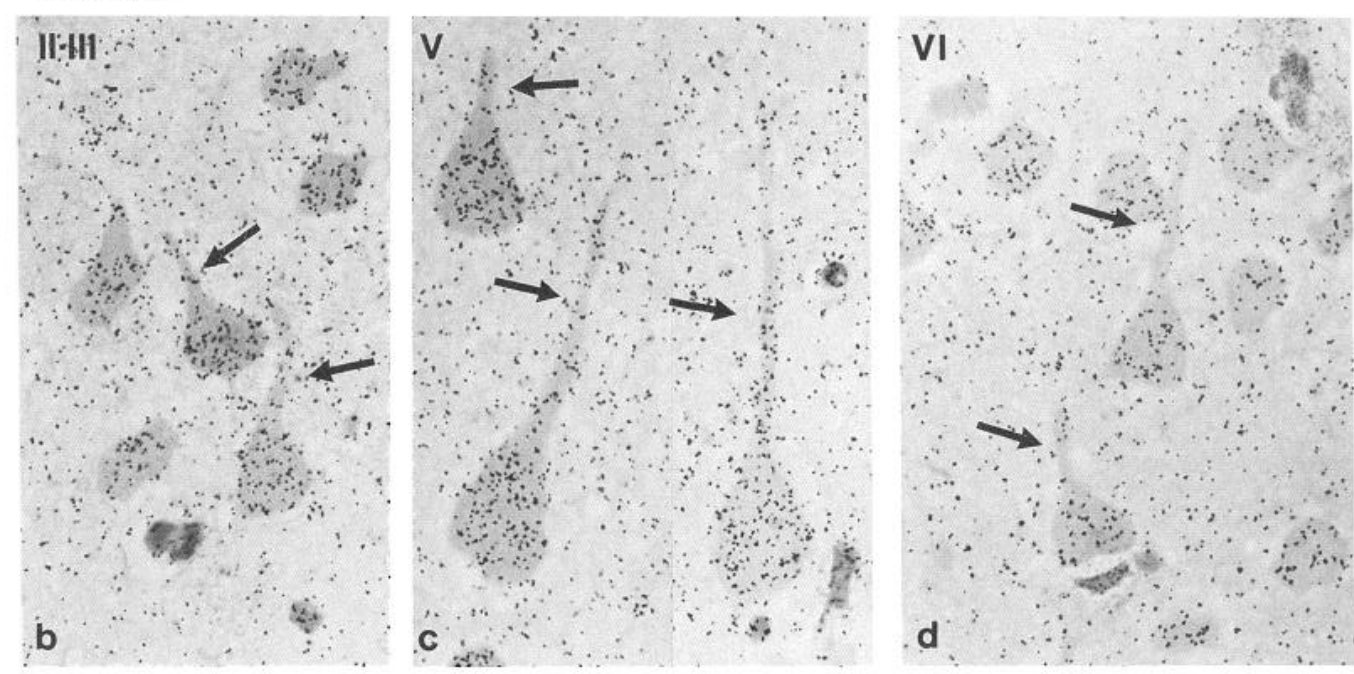

\section{t-ACPD}
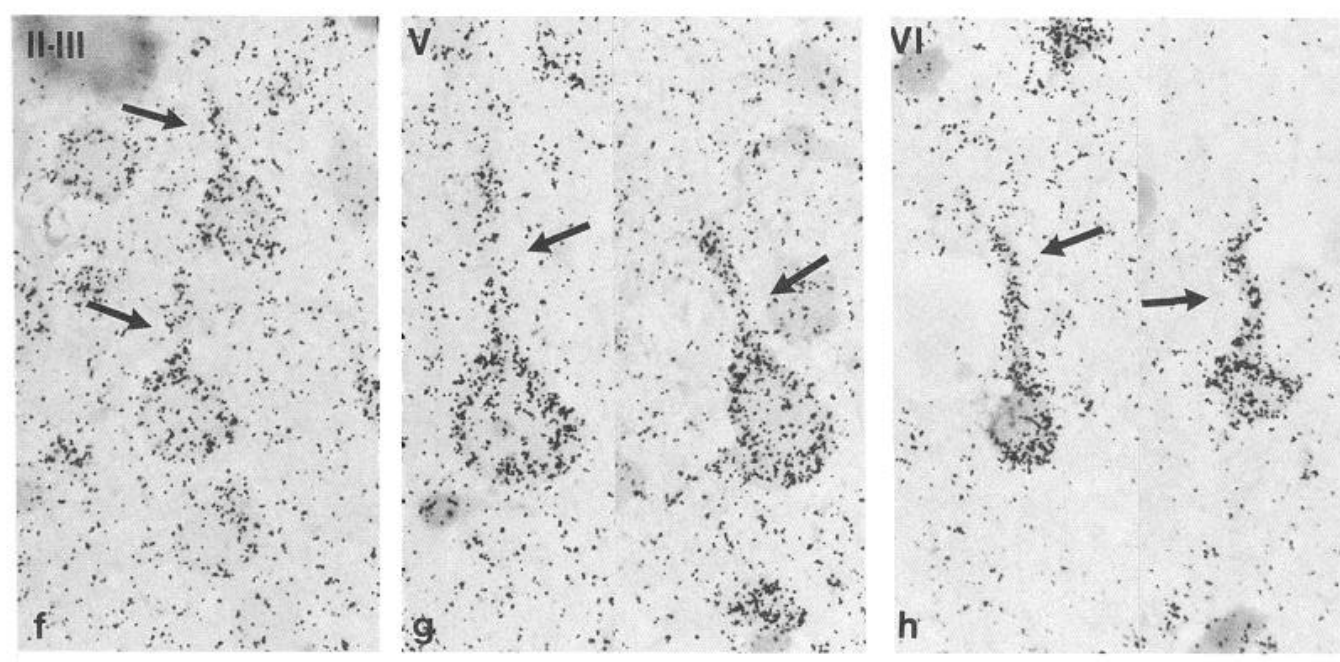

\section{Carbachol}
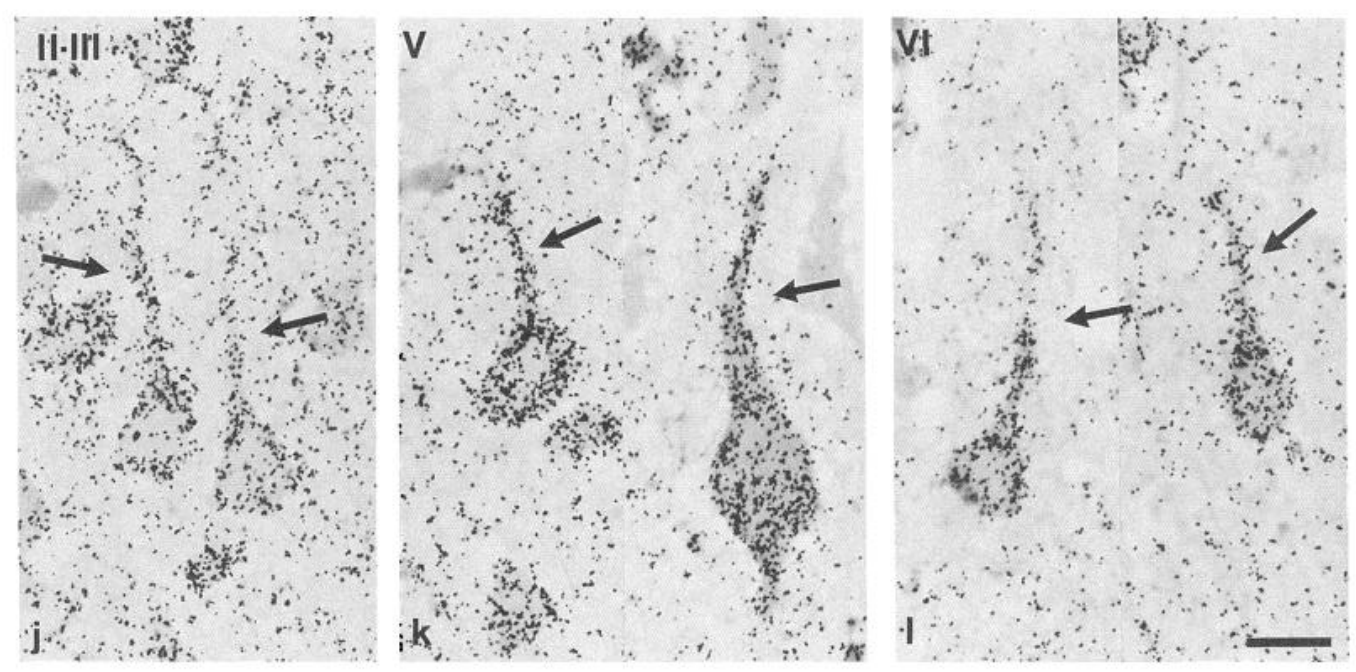

Figure 4. 
bridge) as described in Materials and Methods. In $3 \mathrm{~d}$ old cortical slices the neuropil in cortical plate was not considered since it is almost completely absent. The results shown in Tables 1 and 2 are in general agreement with, and provide further support to the morphological observations described above and illustrated by the figures presented in the previous section.

At P3, two experiments were analyzed. In neurons of the cortical plate, carbachol $2 \mathrm{mM}$ in the presence of lithium induced an accumulation of grains that was statistically different from lithium alone incubations. This labeling was also positive in layers V and VI. In contrast to $t$-ACPD-induced labeling in the presence of lithium, carbachol also induced labeling in the neuropil of layers I, V, and VI at P3. Slices incubated with $t$-ACPD in the presence of lithium showed a higher density of grains overlying neurons of layer $\mathrm{V}$ compared to control incubations with lithium alone. Labeling of the cortical plate and layer VI was not significant in comparison to lithium controls. At this age, $t$-ACPD in the presence of lithium did not induce labeling in the neuropil of any of the layers examined.

At $P 7$, carbachol $2 \mathrm{mM}$ in the presence of lithium $20 \mathrm{mM}$ induced a statistically significant labeling of all layers in which silver grains werc quantificd for both neurons and neuropil. By contrast, at P7, $t$-ACPD $0.2 \mathrm{~mm}$ in the presence of lithium 20 $\mathrm{mM}$, induced labeling that was statistically different from lithium alone incubations only in neurons of layer V. Neurons of all other layers and neuropil throughout the cortex (including layer $\mathrm{V}$ neuropil) were not statistically different from lithium controls.

At P10, muscarinic receptor stimulation in the presence of lithium induced labeling in neurons of layer II-III and V and layer VI. Carbachol also induced labeling of neuropil throughout the cortex. At P10,t-ACPD $0.2 \mathrm{~mm}$ in the presence of lithium $20 \mathrm{mM}$ induced labeling of the neurons in layers II-III, layer V, and layer VI, and in the neuropil of layers II-III, V, and layer VI.

\section{Biochemical analysis}

Agonist-induced accumulation of ${ }^{3} \mathrm{H}$-PtdCMP and ${ }^{3} \mathrm{H}$-inositol phosphates were analyzed in cross-chopped slices to compare our morphological data with biochemical results reported by other authors studying neocortical PI metabolism (Gonzales and Crews, 1985; Nicoletti et al., 1986a,b; Dudek and Bear, 1989; Dudek et al., 1989; Rooney and Nahorski, 1989; Balduini et al., 1991). These assays were run simultaneously in duplicate.

Accumulation of ${ }^{3} \mathrm{H}$-PtdCMP in cross-chopped cortical slices (as fold increase over buffer alone incubations), proved to be age dependent (Fig. 4). Carbachol $2 \mathrm{mM}$ in the presence of lithium $20 \mathrm{~mm}$, induced a peak in the response at P7. The accumulation was lower at P3, 58.25 \pm 3.77-fold increase (mean \pm SEM, $n=2$ ), reached a maximum at P7, $88.3 \pm 0.15$-fold increase (mean $\pm \mathrm{SEM}, n=2$ ), and decreased slowly afterwards, 82.4 \pm 2.3-fold increase at P10 and 23.5 \pm 1.9-fold increase at P14 (mean $\pm \mathrm{SEM}, n=2$ ). Metabotropic glutamate receptor stimulation with $0.2 \mathrm{mM} t$-ACPD in the presence of 20 mM lithium showed a similar age dependency displaying a peak in the response induced at P7. The fold increase detected was $7.85 \pm 0.4$ at P3, 43.25 \pm 6.65 at P7, $30.8 \pm 3.9$ at P10, and $12.5 \pm 0.4$ at P14 (mean $\pm \mathrm{SEM}, n=2$ ). However, after mGIuR stimulation, the absolute levels of ${ }^{3} \mathrm{H}$-PtdCMP accumulation induced were substantially lower than muscarinic receptor stimulation at all ages. Furthermore, percentage wise carbachol's increase between $\mathrm{P} 3$ and $\mathrm{P} 7$ is only 1.5 times, while the $t$-ACPD induced increase grew six times during the same period.
Similar findings were observed in the agonist induced accumulation of ${ }^{3} \mathrm{H}-\mathrm{Ins} P_{1-4}$ combined fraction (Fig. 5). However, in this case the levels of the response induced with all agonists were remarkably lower than for ${ }^{3} \mathrm{H}$-PtdCMP. Carbachol $2 \mathrm{~mm}$ in the presence of lithium $20 \mathrm{~mm}$ induced a $5.44 \pm 0.61$-fold increase (mean $\pm \mathrm{SEM}, n=3$ ) at $\mathrm{P} 3$ reaching to $9.19 \pm 0.64$ (mean $\pm \mathrm{SEM}, n=2$ ) at P7, when the response was maximal. After $\mathrm{P} 7$ the accumulation induced decreased progressively being $7.94 \pm 1.48$ (mean $\pm \mathrm{SEM}, n=2$ ) fold increase at P10 and $4.39 \pm 1.25$ (mean \pm SEM, $n=2$ ) fold increase at P14. The accumulation of ${ }^{3} \mathrm{H}$-Ins $P_{1-4}$ combined fraction induced by $t$-ACPD $0.20 \mathrm{~mm}$ in the presence of lithium $20 \mathrm{~mm}$ was very low at P3, $2.72 \pm 0.88$ (mean $\pm \mathrm{SEM}, n=2$ ) fold increase, it increased progressively, $5.2 \pm 1.68$ (mean $\pm \mathrm{SEM}, n=2$ ) fold increase at $\mathrm{P} 7$, to reach a peak at $\mathrm{P} 10$, when the increment was of $8.23 \pm 0.73$ (mean $\pm \mathrm{SEM}, n=2$ ) fold increase, after P10 the levels progressively decreased to reach basal levels, $3.44 \pm$ 1.25 (mean \pm SEM, $n=2$ ) fold increase at P14.

\section{Discussion}

The present results demonstrate for the first time that, when mGluRs stimulation of PI turnover in neocortical pyramidal cells is examined, this stimulation is limited to pyramidal neurons of layer $\mathrm{V}$ at early stages of postnatal development (P3-P7). It will later spread to both pyramidal neurons and neuropil of layers IIIII, V, and VI at P10, to decline around P14. These results strongly suggest a transient role for metabotropic glutamate receptor linked to PI turnover in layer V pyramidal neurons during early cortical development. While our technique (Bevilacqua et al., 1994) can detect changes occurring within neocortical pyramidal cells, it still has to be perfected to also detect changes within nonpyramidal neocortical cells, a further technical advance which is currently being developed in our laboratory. Although ontogenic and cell type changes in the metabolic fate of receptor-coupled phosphoinositide turnover in the CNS has been previously proposed (Heacock et al., 1990), no direct morphological evidence of such variations had been presented so far. Our results demonstrate a markedly agc- and agonist-dependency in the pattern of labeling of different layers and structures of the rat neocortex.

The studies to assess both ${ }^{3} \mathrm{H}-\mathrm{PtdCMP}$ and ${ }^{3} \mathrm{H}$-inositol phosphates $_{1-4}$ accumulation carried out in parallel at P3, P7, P10 and P14 indicate that the level of accumulation of ${ }^{3} \mathrm{H}$-PtdCMP and ${ }^{3} \mathrm{H}$-inositol phosphates in response to the two agonists used is age-dependent. Stimulation is low at $3 \mathrm{~d}$, peaks between 7 and $10 \mathrm{~d}$ after birth, and decreases afterwards. These data are consistent with many other reports (Gonzales and Crews, 1985; Nicoletti et al., 1986a,b; Dudek and Bear, 1989; Dudek et al., 1989; Rooney and Nahorski 1989; Balduini et al., 1991) in which inositol phosphate stimulation was studied in rat cortex after muscarinic and metabotropic glutamate receptor stimulation in the presence of lithium. Our results suggest that the peak in PI response extends up to P10 decreasing thereafter. We conclude that the ability of the cortex to respond with increased phosphoinositide turnover after specific receptor stimulation is transiently augmented during a narrow period of postnatal development between $\mathrm{P} 7$ and $\mathrm{P} 10$ in rat somatosensory cortex. Moreover, the two assays employed for biochemical analysis, $\operatorname{Ins} P_{1-4}$ and PtdCMP accumulation, respectively, appear to be functionally and developmentally equivalent.

Immunocytochemical and in situ hybridization studies for the two subtypes of mGluRs coupled to phosphoinositide turnover 


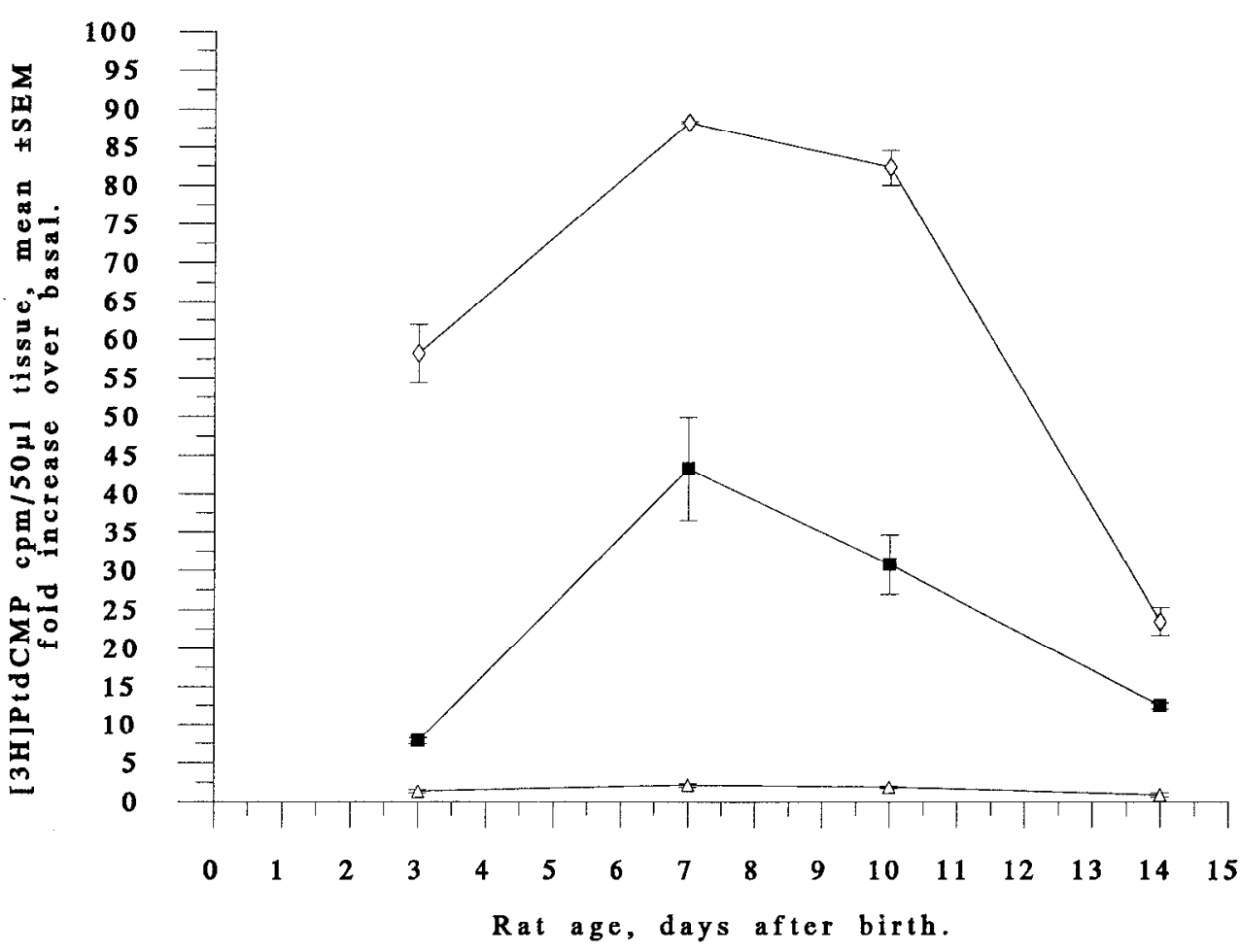

$\triangle$ Lithium $10 \mathrm{mM},-\mathrm{t}-\mathrm{ACPD} 0.2 \mathrm{mM}+\mathrm{Li}+10 \mathrm{mM}$,
$\neg$ Carbachol $2 \mathrm{mM}+\mathrm{Li}+10 \mathrm{mM}$.
Figure 5. ${ }^{3} \mathrm{H}-\mathrm{PtdCMP}$ accumulation in response to lithium, muscarinic-, or metabotropic glutamate-receptor stimulation in the presence of lithium during early postnatal development in rat somatosensory cortex "cross chopped slices." Values are expressed as cpm/ $50 \mu \mathrm{l}$ of gravity packed tissue \pm SEM, and as fold increase over the basal condition (buffer incubation). Incubation conditions were as depicted in the figure. Each value represents the mean of at least two experiments. These experiments were performed in parallel with ${ }^{3} \mathrm{H}$-inositol $P_{1-4}$ induced labeling assays, (Fig. 6).
(mGluR1 and mGluR5) have demonstrated the presence of these receptors in the cortex of neonate rats during the time window we studied (Abe et al., 1992; Shigemoto et al., 1992; Fotuhi et al., 1993; Shigemoto et al., 1993). Expression of mGluR5 is higher at P6 than adult cortex and it predominates over mGluR1 at all ages (Abe et al., 1992; Shigemoto et al., 1992); furthermore, Shigemoto and colleagues (1992), did not find detectable levels of expression of mRNA for mGluR1 before P11, when it rcaches adult levels. These data are in general concordance with our results and suggest that the labeling detected in our cortical preparations possibly represents chiefly $t$-ACPD stimulation of mGluR5 receptors.

Labeling obtained after muscarinic receptor stimulation which is mediated by $M_{1}$ and $M_{3}$ cholinergic receptor subtypes, was more intense than for mGluRs at all ages studied. Pyramidal neurons and neuropil labeling in layers II-III, V and VI was stronger at P7. Neuropil was labeled throughout the cortex including layer I, but the labeling was more intense in layers IIIII and V. This pattern of distribution of the radioactivity after muscarinic receptor stimulation correlates with in situ hybridization, autoradiographic and immunocytochemical studies of muscarinic receptor subtypes (Buckley et al., 1988; Levey et al., 1991). $M_{3}$ receptors are localized predominantly in mid cortical layers (III-V) while $\mathrm{M}_{1}$ receptors are more abundant in layers I, II-, and VI; however, variations in the activity and expression of muscarinic receptors during development have also been reported (Shaw et al., 1984; Parnavelas and Cavanagh, 1988; van Huizen et al., 1994). Taken together with the data reported here, we show the existence of a significant correlation of cellular PI responses with several developmental processes occurring within the rat neocortex. Both biochemical and morphological results indicate the presence of a peak in the ability of the cortex to metabolize phosphoinositide derived second messengers in response to specific receptor stimulation. Remarkably, this peak happens soon after the arrival of subcortical (Lund and Mustari, 1977; Dinopulos et al., 1989) and callosal (Floeter and Jones, 1985) afferents to the cortex, which have been previously proposed to induce a phase of rapid growth of cortical dendrites (Uylings et al., 1990). In addition, a large increase in synapse formation has also been observed to coincide with the rise in the formation of dendrites of pyramidal and nonpyramidal neurons that occurs also at this time (Blue and Parnavelas, 1983a,b).

The selective labeling of layer $\mathrm{V}$ pyramidal neurons following $t$-ACPD stimulation of PI turnover at P3 and P7 suggests that cell growth and arborization of the dendritic trees which occur simultaneously with an increase in the formation of synapses (Miller, 1988; Uylings et al., 1990), could occur earlier for layer $\mathrm{V}$, thus suggesting an important role for pyramidal neurons in this layer in coordinating the processes that lead to the growth and establishment of the neocortical circuitry. Furthermore, PI derived second messengers have been proposed to be a common final metabolic pathway that links receptor activation with synaptic plasticity (e.g., noradrenaline, $\mathrm{ACh}$, and glutamate are necessary for synaptic plasticity to occur) (Shaw et al., 1984; Bear and Singer, 1986; Kleinschmidt et al., 1987; Dudek and Bear, 1989; Dudek et al., 1989; Rauschecker, 1991). Therefore, the morphological evidence presented in this work proposes that layer $\mathrm{V}$ pyramidal neurons might represent one of the initial targets of this co-ordinated neurotransmitter activity, and might constitute one of the layers where cortical maturation processes begin.

In addition, very recently, two groups have shown that in both 
Figure 6. ${ }^{3} \mathrm{H}$-Inositol $P_{1-4}$ combined fraction accumulation in response to lithium, muscarinic-, or metabotropic glutamate-receptor stimulation in the presence of lithium during early postnatal development in rat somatosensory cortex "cross chopped slices." Values are expressed as cpm/50 $\mu$ l of gravity packed tissue \pm SEM, and as fold increase over the basal condition (buffer incubation). Incubation conditions were as depicted in the graphic. Each value represents the mean of at least two experiments. These experiments were performed in parallel with ${ }^{3} \mathrm{H}$-PtdCMP induced labeling assays (Fig. 5).

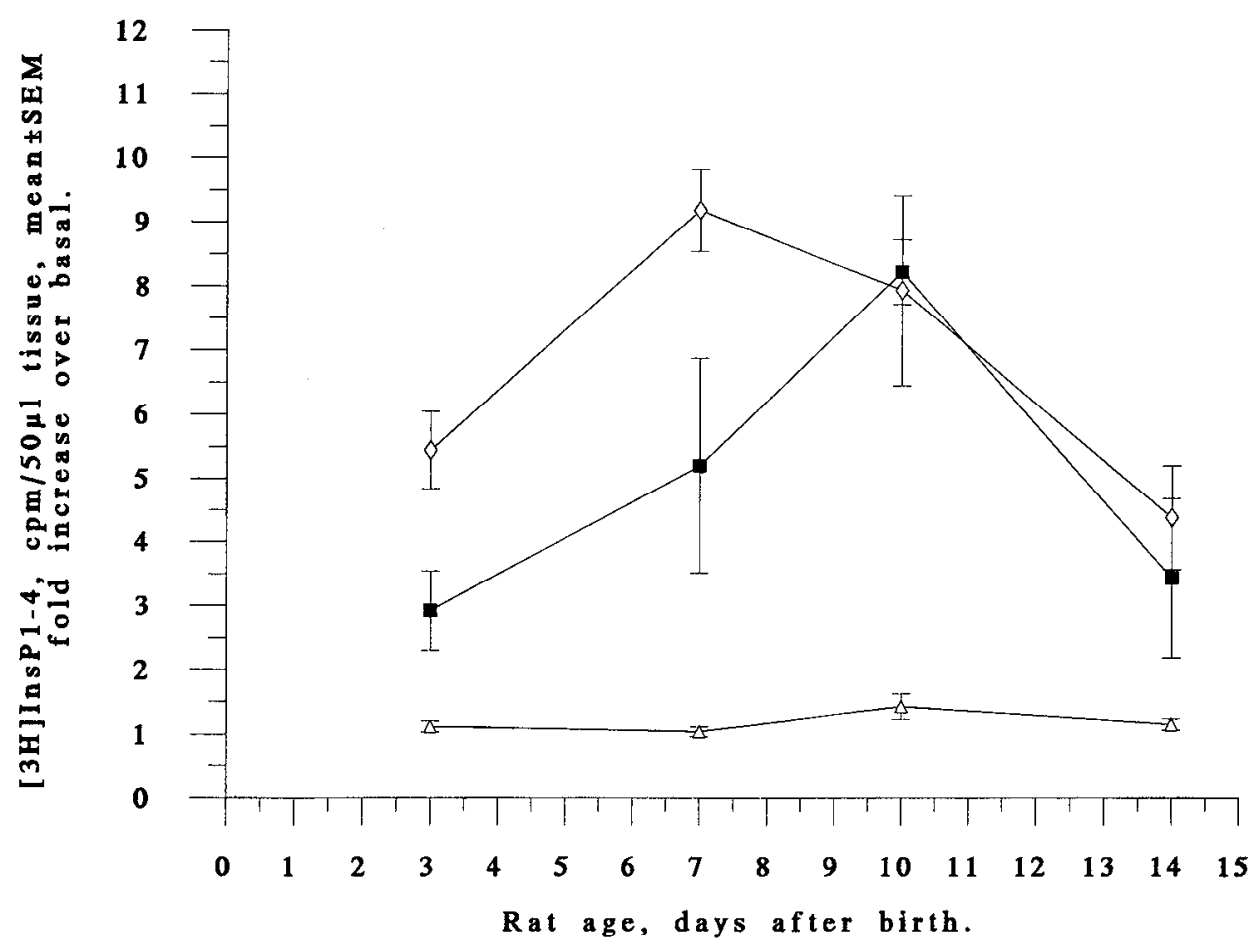

$\multimap$ Lithium $10 \mathrm{mM}, \rightarrow \mathrm{t}-\mathrm{ACPD} 0.2 \mathrm{mM}+\mathrm{Li}+10 \mathrm{mM}$,
$\neg$ Carbachol $2 \mathrm{mM}+\mathrm{Li}+10 \mathrm{mM}$. somatosensory and visual cortex of the rat the critical period correlates with electrophysiologically induced LTP (Crair and Malenka, 1995; Kirkwood et al., 1995). Interestingly, LTP can only be induced in somatosensory cortex between postnatal days $3-7$, while in visual cortex it can only be recorded between days 14-21. Thus, while induction of LTP correlates with the critical period, its induction appears to follow an antero-posterior developmental gradient. Also, different stimulation paradigms have been used by both groups. The paper studying somatosensory cortex (Crair and Malenka, 1995) has examined the thalamocortical synapses of layer IV, while Kirkwood et al. have examined responses in layer III after stimulation of the white matter, a response in which layer $\mathrm{V}$ neurons are implicated (see Stryker, 1995). Thus, these results correlate overall with ours, in that our responses occur during the same time-window than the cortical critical period, induction of LTP, and affect neurons which could be contributing to the LTP responses involved.

In addition, given that the critical period in rat visual cortex is delayed compared to neurotransmitter induced PI turnover changes we have studied in the somatosensory cortex, we would like to suggest that either (1) the second messenger changes discussed in the present article are unrelated to mechanisms involved in sensory-dependent plasticity in the visual cortex, or (2) that if similar experiments to those we report here for somatosensory cortex, were repeated in visual cortex, the peak in PI turnover might well be delayed when compared to our results on somatosensory cortex, following the gradient of induced LTP during neocortical development.

As presented in the introduction, two main hypothesis could explain the peak in the induced PI response detected biochemically (Fig. $1 A, B$ ). In this report we propose that the peak in the phosphoinositide response during neocortical development is generated according to a combination of both possibilities, depending on the agonist and the age of the animals examined. Muscarinic receptor induced phosphoinositide turnover occurs throughout all cortical layers at all ages studied. By contrast, mGluRs stimulation of phosphatidylinositol 4,5-bisphosphate breakdown and the generation of derived second messengers occurs in a layer specific fashion, starting by an initial selective stimulation of neurons of layer V at P3-P7, and then extending into the neuropil and neurons of the other cortical layers as age increases (Fig. 7).

It has been known for some time that neurotransmitters exert trophic effects in the CNS (Felten et al., 1982; Lauder, 1993). In addition it has been recently demonstrated that stimulation of metabotropic glutamate receptors induces protein synthesis in neurons (Weiler et al., 1993). Moreover, it has been shown that other trophic factors such as NGF affect visual cortical plasticity (Gu et al., 1994). Thus, the rapid growth and maturation phase experienced by the cortex during the first postnatal weeks, is probably under the regulation of multiple factors that determine simultaneously its growth and differentiation. According to our results, activation of $\operatorname{PtdIns} P_{2}$ derived second messengers could represent a final common pathway acting as a central component of this coordinated neuromodulatory effect.

How could changes in layer $\mathrm{V}$ be relayed back to the developing neocortex? At present we can envisage two pathways by which this could be accomplished: (1) through inputs from layer $\mathrm{V}$ to layer VI, which innervates layer IV neurons, which in turn provide input to supragranular neurons, or, alternatively through (2) the subplate/intermediate zone neurons, which relay back to the developing cortex proper (Friauf and Shatz, 1991), and 
Carbachol

P3

II

IV

II

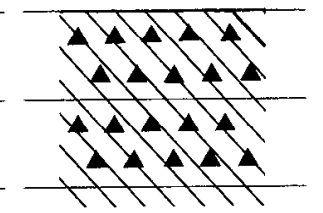

WM
$t$-ACPD

P3

\begin{tabular}{ll}
\hline I \\
\hline II \\
III \\
\hline IV \\
\hline V \\
\hline VI
\end{tabular}

P7

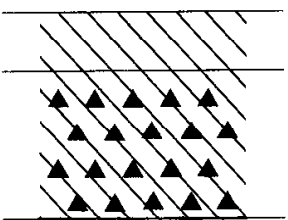

P10
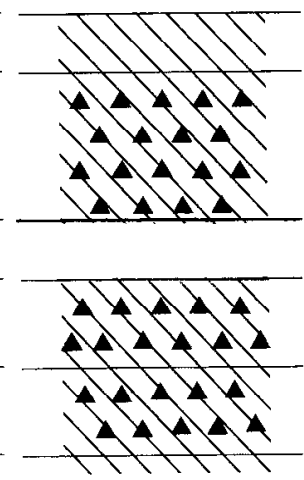

WM
P7

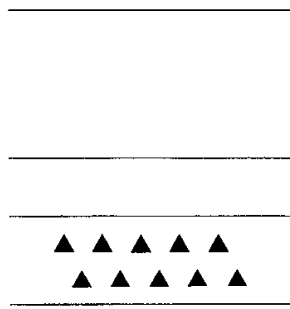

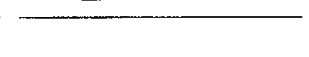

P10

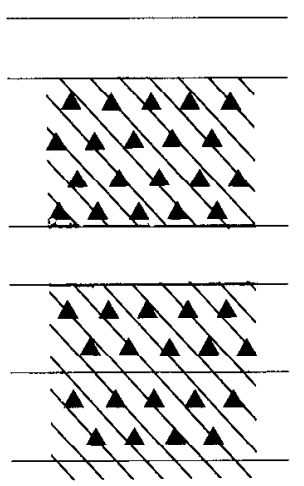

Figure 7. Schematic representation of the morphological results obtained. Carbachol in the presence of lithium induced labeling in neurons and neuropil throughout the cortex at all ages studied. $t$-ACPD in the presence of lithium induced labeling only in neurons of layer $\mathrm{V}$ at $\mathrm{P} 3$ and $\mathrm{P} 7$, but labeling was found in neurons and neuropil of layers II-III, V, and VI at P10. Thus, the hypothesis shown in figure $1 \mathrm{~B}$ accounts for neurotransmitter induced PI turnover at $\mathrm{P} 3$ and $\mathrm{P} 7$, while the one depicted in Figure $1 A$ accounts for neurotransmitter induced PI turnover at P10. Roman numerals indicate cortical layers; $W M$, white matter; $\boldsymbol{\Delta}$, labeled neurons; the diagonal strip pattern represents neuropil labeling.

which we have recently shown receives direct cortical input from layers V/VI of the developing cortex (Shering and Lowenstein, 1994; see also Stryker, 1995). Thus, interconnections centred around layer $\mathrm{V}$ could play an important role in regulating neocortical maturation during early development.

In summary, the main contribution of the present work is the morphological identification for the first time of those cortical cells sustaining the transient neurotransmitter induced peak in PI-turnover during early neocortical development. These findings, therefore, provide a possible anatomical substrate underlying neocortical changes in second messengers activity during early cortical development. Further work will now contribute to unravel the central role played by phosphoinositide turnover signal transduction activation and layer $\mathrm{V}$ pyramidal neurons during cortical development.

\section{References}

Abe T, Sugiara $H$, Nawa $H$, Shigemoto R, Mizuno N, Nakanishi $S$ (1992) Molccular characterisation of a novel metabotropic glutamate receptor mGluR5 coupled to inositol phosphate/Ca ${ }^{++}$signal transduction. J Biol Chem 267:13361-13368.

Balduini W, Candura SM, Costa LG(1991) Regional development of carbachol-, glutamate-, norepinephrine-, and serotonin-stimulated phosphoinositide metabolism in rat brain. Dev Brain Res 62:115120.

Bear MF, Dudek SM (1991) Stimulation of phosphoinositide turnover by excitatory amino acids. Ann NY Acad Sci 627:42-56.

Bear MF, Singer W (1986) Modulation of visual cortical plasticity by acetylcholine and noradrenaline. Nature 320:172-176.
Berridge MJ, Downes CP, Hanley MR (1982) Lithium amplifies agonist-dependent phosphatidylinositol responses in brain and salivary glands. Biochem J 206:587-595.

Bevilacqua JA, Downes CP, Lowenstein PR (1994) Visualization of agonist-stimulated inositol phospholipid turnover in individual neurons of the rat cerebral cortex and hippocampus. Neuroscience 60: 945-958.

Blakemore C, Van Sluyters RC (1974) Reversal of the physiological effects of monocular deprivation in kittens: further evidence for a sensitive period. J Physiol (Lond) 237:195-216.

Blue ME, Johnston MV (1994) The ontogeny of glutamate receptors in rat barrel field cortex. Dev Brain Res 84:11-25.

Blue ME, Parnavelas JG (1983a) The formation and maturation of synapses in the visual cortex of the rat. I. Qualitative analysis. I Neurocytol 12:599-616.

Blue ME, Parnavelas JG (1983b) The formation and maturation of synapses in the visual cortex of the rat. II. Quantitative analysis. J Neurocytol 12:697-712.

Buckley NJ, Bonner TI, Brann MR (1988) Localisation of a family of muscarinic receptor mRNAs in rat brain. J Neurosci 8:4646 4652 .

Cortés R, Palacios JM (1986) Muscarinic receptor subtype in the rat brain: quantitative autoradiographic studies. Brain Res 362:227-238.

Crair MC, Malenka RC (1995) A critical period for long-term potentiation at thalamocortical synapses. Nature 375:325-328.

Cynader M, Mitchell DE (1980) Prolonged sensitivity to monocular deprivation in dark reared cats. J Neurophysiol 43:1026-1040.

Daw NW, Fox K, Sato H, Czepita D (1992) Critical period for monocular deprivation in the cat visual cortex. J Neurosci 67:197-202.

Dinopulos A, Eadie LA, Dori I, Parnavelas JG (1989) The development of the basal forebrain projections to the rat visual cortex. Exp Brain Res 76:563-571.

Dudek SM, Bear MF (1989) A biochemical correlate of the critical 
period for synaptic modification in the visual cortex. Science 246 : 673-675.

Dudek SM, Bowen WD, Bear MF (1989) Postnatal changes in glutamate stimulated phosphoinositide turnover in rat neocortical synaptoneurosomes. Dev Brain Res 47:123-128.

Faglioni M, Pizzorusso T, Berardi N, Domenici L, Maffei L (1994) Functional postnatal development of the rat primary visual cortex and the role of visual experience: dark rearing and monocular deprivation. Vision Res 6:709-720.

Felten DL, Hallman H, Jonsson G (1982) Evidence for a neurotrophic role of noradrenaline neurons in postnatal development of the rat cortex. J Neurocytol 11:119-135.

Floeter MK, Jones EG (1985) The morphology and phased outgrowth of callosal axons in the fetal rat. Dev Brain Res 22:7-18.

Fotuhi M, Sharp AH, Glatt CE, Hwang PM, von Krosig M, Snyder SH (1993) Differential localisation of phosphoinositide-linked metabotropic glutamate receptor (mGluR1) and the inositol 1,4,5-trisphosphate receptor in rat brain. J Neurosci 13:2001-2012.

Fox K (1992) A critical period for experience-dependent synaptic plasticity in rat barrel cortex. J Neurosci 12:1826-1838.

Fox K, Zahs K (1994) Critical period in sensory cortex. Comp Neurobiol 4:112-119.

Friauf E, Shatz CJ (1991) Changing patterns of synaptic input to subplate and cortical plate during development of visual cortex. J Neurophysiol 66:2059-2071.

Gonzales RA, Crews FT (1985) Cholinergic-and adrenergic-stimulated inositide hydrolysis in brain: interaction, regional distribution, and coupling mechanisms. J Neurochem 45:1076-1084.

Gu Q, Liu Y, Cynader MS (1994) Nerve growth factor-induced ocular dominance plasticity in adult cat visual cortex. Proc Natl Acad Sci USA 91:8408-8412.

Heacock AM, Seguin EB, Agranoff BW (1990) Developmental and regional studies in the metabolism of inositol 1,4,5-trisphosphate in rat brain. J Neurochem 54:1405-1411.

Hubel DH, Wiesel TN (1970) The period of susceptibility to the phys iological effects of unilateral eye closure in kittens. J Physiol (Lond) 206:419-436.

Kirkwood A, Lee HK, Bear MF (1995) Coregulation of long-term potentiation and experience-dependent synaptic plasticity in visual cortex by age and experience. Nature 375:328-331.

Kleinschmidt A, Bear MF, Singer W (1987) Blockade of "NMDA" receptors disrupts experience-dependent plasticity of kittens striate cortex. Science 238:355-358.

Lauder JM (1993) Neurotransmitters as growth regulatory signals: role of receptors as second messengers. Trends Neurosci 16:233-240.

Le Vay S, Hubel DH, Wiesel TN (1980) The development of ocular dominance columns in normal and visually deprived monkeys. J Comp Neurol 191:1-51.

Levey AI, Kitt CA, Simonds WF, Price DL, Brann MR (1991) Identification and localisation of muscarinic acetycholine receptor proteins in brain with subtype specific antibodies. J Neurosci 11:32183226.

Levitt P, Moore RY (1979) Development of the noradrenergic innervation of neocortex. Brain Res 162:243-259.

Lund RD, Mustari MJ (1977) Development of geniculocortical pathways in rats. J Comp Neurol 173:289-306.

Miller MW (1988) Development of projections and local circuit ncurons in neocortex. In: Cerebral cortex, Vol 7, Development and maturation of cerebral cortex (Peters A, Jones EG, eds), pp 133-176. New York: Plenum.
Morris MJ, Dausse JP, Devync MA, Meyer P (1980) Ontogeny of $\alpha 1$ and $\alpha 2$-adrenoreceptors in ral brain. Brain Res 190:268-271.

Nicoletti F, Iadarola MJ, Wroblewski JT, Costa E (1986a) Excitatory amino acid recognition sites coupled with inositol phospholipid metabolism: developmental changes and interaction with $\alpha 1$-adrenoreceptors. Proc Natl Acad Sci USA 83:1931-1935.

Nicoletti F, Meek JL, Iadarola MJ, Chuang DM, Roth BL, Costa E (1986b) Coupling of inositol phospholipid metabolism with excitatory amino acid recognition sites in rat hippocampus. J Neurochem 46 : $40-46$.

Parnavelas JG, Cavanagh ME (1988) Transient expression of neurotransmitters in the developing cortex. Trends Neurosci 11:92-93.

Rauschecker JP (1991) Mechanisms of visual plasticity: Hebb synapses, NMDA receptors and beyond. Physiol Rev 71:587-615.

Rooney TA, Nahorski SR (1989) Developmental aspects of muscarinic-induced inositol polyphosphate accumulation in rat cerebral cortex. Eur J Pharmacol 172:425-434.

Schlaggar BL, Fox K, O'Leary DDM (1993) Post synaptic control of plasticity in developing somatosensory corlex. Nature 364:623-626.

Shaw C, Cynader M (1984) Disruption of cortical activity prevents ocular dominance changes in monocularly deprived kittens. Nature 308:731-734.

Shaw C, Needler MC, Cynader MS (1984) Ontogenesis of muscarinic acetilcholine binding sites in cat visual cortex: reversal of specific laminar distribution during the critical period. Dev Brain Res 14:295299.

Shering AF, Lowenstein PR (1994) Neocortex provides direct synaptic input to interstitial neurons of the intermediate zone of kittens and white matter of cats: a light and electron microscopic study. J Comp Neurol 347:433-443.

Shigemoto R, Nakanishi S, Mizuno N (1992) Distribution of the mRNA for a metabotropic glutamate receptor (mGluR1) in the central nervous system: an in situ hybridisation study in adult and developing rat. J Comp Neurol 322:121-125.

Shigemoto R, Nomura S, Ohishi H, Sugihara H, Nakanishi S, Mizuno N (1993) Immunohistochemical localisation of a metabotropic glutamate receptor, mGluR5, in the rat brain. Neurosci Lett 163:53-57.

Spencer DG, Norváth E, Traber J (1986) Direct autoradiographic determination of $M 1$ and $M 2$ muscarinic acetylcholine receptor distribution in the rat brain: relation to cholinergic nuclei and projections. Brain Res 380:59-68.

Stephens LR, Hughes KT, Irvine RF (1991) Pathway of phosphatidylinositol $(3,4,5)$-trisphosphate synthesis in activated neutrophils. Nature 351:33-39.

Stryker MP (1995) Growth through learning. Nature 375:277-278.

Uylings HBM, Van Eden CG, Parnavelas JG, Kalsbeek A (1990) The prenatal and postnatal development of rat cerebral cortex. In: The cerebral cortex of the rat (Kolb B, Tees RC, ed), pp 35-76. Cambridge, MA: MIT Press.

Van der Loos H, Woolsey TA (1973) Somatosensory cortex: structural alterations following early injury to sense organs. Science 179:395 398.

van Huizen F, March D, Cynader MS, Shaw C (1994) Muscarinic receptor characteristics and regulation in rat cerebral cortex: changes during development, ageing and oestrus cycle. Eur J Neurosci 6:237 243.

Weiler IJ, Greenough WT (1993) Metabotropic glutamate receptors trigger post synaptic protein synthesis. Proc Natl Acad Sci USA 90: 7168-7171.

Woolsey TA, Wann JR (1976) Areal changes in mouse cortical barrels following vibrissal damage at different postnatal ages. J Comp Neurol 1 $\%$ 0:53-66. 